\title{
Disruption of tissue-type plasminogen activator gene in mice reduces renal interstitial fibrosis in obstructive nephropathy
}

\author{
Junwei Yang, Ryan W. Shultz, Wendy M. Mars, Rodney E. Wegner, Yingjian Li, \\ Chunsun Dai, Kari Nejak, and Youhua Liu
}

Division of Cellular and Molecular Pathology, Department of Pathology, University of Pittsburgh School of Medicine, Pittsburgh, Pennsylvania, USA

\begin{abstract}
Tissue-type plasminogen activator (tPA) is one of the major components in the matrix proteolytic network whose role in the pathogenesis of renal interstitial fibrosis remains largely unknown. Here, we demonstrate that ablation of tPA attenuated renal interstitial fibrotic lesions in obstructive nephropathy. Mice lacking tPA developed less morphological injury and displayed a reduced deposition of interstitial collagen III and fibronectin as well as total tissue collagen in the kidneys after sustained ureteral obstruction, when compared with their wild-type counterparts. Deficiency of tPA selectively blocked tubular epithelial-to-myofibroblast transition (EMT), but did not affect myofibroblastic activation from interstitial fibroblasts. A marked decrease in matrix metalloproteinase-9 (MMP-9) induction was found in the obstructed kidneys of $t P A^{-/-}$mice, which led to a dramatic preservation of the structural and functional integrity of tubular basement membrane (TBM). In vitro, tPA induced MMP-9 gene expression and protein secretion in renal interstitial fibroblasts. Thus, increased tPA is detrimental in renal interstitial fibrogenesis through a cascade of events that lead to MMP-9 induction, TBM destruction, and promotion of EMT. Our findings establish a crucial and definite importance of EMT in the pathogenesis of renal interstitial fibrosis at the whole-animal level.
\end{abstract}

J. Clin. Invest. 110:1525-1538 (2002). doi:10.1172/JCI200216219.

\section{Introduction}

Tissue-type plasminogen activator (tPA) is an essential component of the proteolytic cascade in blood coagulation and fibrinolysis. It also plays a pivotal role in the maintenance of the delicate balance between extracellular matrix production and degradation in vivo. The main function of tPA is to cleave plasminogen into biologically active plasmin. Plasmin, in turn, not only directly degrades matrix components, but also amplifies the proteolytic potential by converting matrix metalloproteinases (MMPs) from their zymogen to active form $(1,2)$. In addition, tPA is implicated in the posttranslational activation of several growth factors, including TGF- $\beta 1$ and $\operatorname{HGF}(3,4)$. Such action may have broader implications in tissue fibrogenesis, because both TGF- $\beta 1$ and HGF are critical regulators of tissue extracellular matrix accumulation and deposition

Received for publication June 19, 2002, and accepted in revised form October 1, 2002.

Address correspondence to: Youhua Liu, Department of Pathology, University of Pittsburgh School of Medicine, S-405 Biomedical Science Tower, 200 Lothrop Street, Pittsburgh, Pennsylvania 15261, USA. Phone: (412) 648-8253; Fax: (412) 648-1916; E-mail: liuy@msx.upmc.edu.

Conflict of interest: The authors have declared that no conflict of interest exists.

Nonstandard abbreviations used: tissue-type plasminogen activator (tPA); matrix metalloproteinase (MMP); $\alpha$-smooth muscle actin ( $\alpha$-SMA); epithelial-to-myofibroblast transition (EMT); tubular basement membrane (TBM); unilateral ureteral obstruction (UUO). that function in an opposite manner (5-7). Given the significance of tPA for matrix homeostasis in multicellular organisms, it is not difficult to comprehend that its expression and activity are tightly regulated through a multitude of controlling mechanisms. Dysregulation of tPA may contribute to the pathogenesis of a wide variety of diseases ranging from tumor metastasis to tissue fibrogenesis.

While the importance of the tPA in matrix proteolytic systems is well documented, its role in the pathogenesis of renal interstitial fibrosis, characterized by excess matrix accumulation and deposition, is poorly defined. Tubular interstitial fibrosis is often regarded as a final, common endpoint outcome of many forms of chronic renal disease $(1,8)$. One of the key events during interstitial fibrogenesis is the de novo activation of $\alpha$-smooth muscle actin-positive ( $\alpha$-SMA-positive) myofibroblast cells. Because these cells are primarily responsible for interstitial matrix accumulation and deposition in chronically diseased states (9-11), and because they are essentially absent in the interstitial compartment of normal kidney (12), elucidation of their origin(s) and the activation process is of fundamental importance both for understanding the pathologic mechanism of renal interstitial fibrosis and for identifying therapeutic targets. Myofibroblasts are often presumed to originate from residential fibroblasts; however, recent evidence suggests that they may also derive from tubular epithelial cells via an epithelial-to-myofibroblast transition (EMT) (13-19). We 
recently proposed that renal EMT is an orchestrated, highly regulated, stepwise process in which destruction of the integrity of the tubular basement membrane (TBM) may be crucial (20). However, whether molecules such as tPA, an upstream regulator of specific MMPs that can degrade TBM, are involved in the destruction of the TBM under pathologic conditions at the whole-animal level remains unknown.

The availability of genetically engineered mice in which the endogenous tPA gene is inactivated provides an invaluable, unprecedented model system to study the function of tPA in the pathogenesis of renal interstitial fibrosis in vivo. In this study, we investigated the progression of renal interstitial fibrosis induced by unilateral ureteral obstruction (UUO) in $t P A^{+/+}$and $t P A^{-/-}$mice. We found that the null mutation of the tPA gene protected kidney from developing interstitial fibrotic lesions. The detrimental effect of endogenous tPA was apparently not mediated by alterations in the expression and activation of profibrogenic TGF- $\beta 1$ in the kidney. Rather, it was likely mediated by upregulating MMP-9 expression, leading to destruction of the TBM which in turn resulted in myofibroblastic transition of tubular epithelial cells via EMT. Our results validate the hypothesis that TBM integrity plays an essential role in preventing tubular EMT, thereby protecting normal renal morphology against development of fibrotic lesions.

\section{Methods}

Animal model. Colonies of homozygous tPA knockout $\left(t P A^{-/-}\right)$and wild-type $\left(t P A^{+/}\right)$mice were raised from original breeding pairs obtained from P. Carmeliet of the University of Leuven, Belgium. They were housed in the animal facilities of the University of Pittsburgh Medical Center with free access to food and water. Animals were treated humanely in accordance with $\mathrm{NIH}$ guidelines and by use of approved procedures of the Institutional Animal Use and Care Committee at the University of Pittsburgh. Genotype was confirmed using PCR amplification of genomic DNA from the tail. The experiments were performed on male $t P A^{-/-}$ and $t P A^{+/+}$mice with identical genetic backgrounds and with an average age of 10 weeks. There was no statistical difference in the body weight of $t P A^{-/-}$and $t P A^{+/+}$mice at the time of the experiments. Both wildtype $\left(t P A^{+/+}\right)$and knockout $\left(t P A^{-/-}\right)$animals were randomly assigned into four groups (with five mice per group): sham surgery for 3 days, UUO for 3 days, sham for 7 days, and UUO for 7 days. UUO was performed by ligating the left ureter using 4-0 silk after a midline abdominal incision, as described elsewhere (21). Sham-operated mice had their ureters exposed and manipulated, but not ligated. Mice were sacrificed at day 3 or day 7 after surgery and kidneys were removed. One part of the kidney was fixed in 10\% phosphatebuffered formalin followed by paraffin embedding for histologic and immunohistochemical studies. Another part was immediately frozen in Tissue-Tek OCT compound (Sakura Finetek, Torrance, California, USA) for cryosection. The remaining kidneys were snap-frozen in liquid nitrogen and stored at $-80^{\circ} \mathrm{C}$ for extraction of RNA and protein.

RNA isolation and Northern blot analysis. Total RNA was extracted from the kidney by a single-step method using an Ultraspec RNA isolation system according to the instructions specified by the manufacturer (Biotecx Laboratories Inc., Houston, Texas, USA). RNA was quantified by determination of ultraviolet absorbance at $260 \mathrm{~nm}$, and its purity was assessed by measuring the OD ratio at 260 and $280 \mathrm{~nm}$. Northern blot analysis for gene expression was carried out by procedures described previously (12). Briefly, samples of $20 \mu \mathrm{g}$ total RNA were electrophoresed on $1.0 \%$ formaldehyde-agarose gels and then transferred to GeneScreen Plus nylon membrane (NEN Life Science Products Inc., Boston, Massachusetts, USA) by capillary blotting. Membranes were prehybridized for 4 hours at $65^{\circ} \mathrm{C}$ in a buffer containing $6 \times \mathrm{SSC}(20 \times \mathrm{SSC}$ is $3 \mathrm{M} \mathrm{NaCl}$ and $0.3 \mathrm{M}$ sodium citrate, $\mathrm{pH} 7.0), 5 \times$ Denhardt's solution (0.1\% Ficoll 400, $0.1 \%$ polyvinylpyrrolidone, and $0.1 \%$ BSA), $1 \%$ SDS, $10 \%$ dextran sulfate, and $100 \mu \mathrm{g} / \mathrm{ml}$ denatured salmon sperm DNA. ${ }^{32}$ P-labeled DNA probes were prepared using the random primer labeling kit from Stratagene (La Jolla, California, USA) using $\left[\alpha^{-32} \mathrm{P}\right] \mathrm{dCTP}$. Denatured probes were added to the same hybridization buffer at concentrations of $1 \times 10^{6}$ to $2 \times 10^{6} \mathrm{cpm} / \mathrm{ml}$, and hybridization was allowed to proceed at $65^{\circ} \mathrm{C}$ for 16 hours. Membranes were washed twice in $2 \times$ SSC with $0.2 \%$ SDS at room temperature for 10 minutes, followed by two washes in $0.1 \times$ SSC with $0.2 \%$ SDS at $65^{\circ} \mathrm{C}$ for 20 minutes. The membranes were then exposed to $x$-ray film at $-80^{\circ} \mathrm{C}$ with the aid of an intensifying screen. After autoradiography, membranes were stripped and rehybridized with rat GAPDH probe to assure equal loading of each lane.

Zymographic analysis. Gelatin zymographic analysis of MMP proteolytic activity in kidney tissue homogenates was performed according to the method described previously (20). Kidney homogenates were prepared essentially according to the methods described by Kim et al. (22). Protein concentration was determined using a bicinchoninic acid (BCA) protein assay kit with BSA as a standard (Sigma-Aldrich, St. Louis, Missouri, USA). A constant amount of protein from the kidney tissue homogenates $(30 \mu \mathrm{g})$ was loaded onto $10 \%$ SDS-polyacrylamide gel containing $1 \mathrm{mg} / \mathrm{ml}$ gelatin (Bio-Rad Laboratories Inc., Hercules, California, USA). After electrophoresis, SDS was removed from the gel by incubation in $2.5 \%$ Triton X-100 at room temperature for 30 minutes with gentle shaking. The gel was washed well with distilled water to remove detergent and incubated at $37^{\circ} \mathrm{C}$ for 16 hours in a developing buffer containing $50 \mathrm{mM}$ Tris- $\mathrm{HCl}$ at $\mathrm{pH} 7.6,0.2 \mathrm{M} \mathrm{NaCl}, 5 \mathrm{mM}$ $\mathrm{CaCl}_{2}$, and $0.02 \% \mathrm{BRIJ} 35$ (Sigma-Aldrich). The gel was then stained with a solution of $30 \%$ methanol, $10 \%$ glacial acetic acid, and 0.5\% Coomassie blue G250, followed by destaining in the same solution without dye. 
Proteinase activity was detected as unstained bands on a blue background representing areas of gelatin digestion. In some experiments, a potent $\left(\mathrm{IC}_{50}=2.7 \mathrm{nM}\right)$ MMP-9 inhibitor, N-hydroxy-1,3-di-(4-methoxybenzenesulphonyl)-5,5-dimethyl-(1,3)-piperazine-2-carboxamide (MMP inhibitor II; Calbiochem-Novabiochem Corp., La Jolla, California, USA) (23), was added to the developing buffer at a concentration of 10 nM to prevent MMP-9 activity.

To detect renal plasmin and plasminogen activities, casein zymographical analysis was employed in the presence or absence of plasminogen, according to methods described elsewhere (24). Briefly, equal amounts of kidney homogenates $(30 \mu \mathrm{g})$ of $t P A^{+/+}$and $t P A^{-/-}$mice were loaded onto $10 \%$ SDS-polyacrylamide gel containing $2 \mathrm{mg} / \mathrm{ml}$ casein in the presence or absence of $10 \mu \mathrm{g} / \mathrm{ml}$ of plasminogen. After electrophoresis, SDS was removed from the gel by washing with $2.5 \%$ Triton X-100 solution. The gel was incubated at $37^{\circ} \mathrm{C}$ for 16 hours in $0.1 \mathrm{M}$ glycine ( $\mathrm{pH} 8.3$ ). After the gels were stained with Coomassie blue G250 as described above, plasminogen activity was revealed as clear lytic bands on a blue background. Purified tPA (American Diagnostica Inc., Greenwich, Connecticut, USA) was loaded in an adjacent lane to confirm the correct size of tPA. In some experiments, aprotinin was included in the incubation buffer to prevent plasmin activity.

Histology and immunostaining. Paraffin-embedded kidney sections were prepared at $4 \mu \mathrm{m}$ thickness by a routine procedure. Sections were stained with hematoxylin and eosin for general histology. Indirect immunofluorescence staining was performed on kidney cryosections using an established procedure. Cryosections were prepared at $5 \mu \mathrm{m}$ thickness and fixed for 5 minutes in PBS containing $3 \%$ paraformaldehyde. After being blocked with $1 \%$ normal donkey serum in PBS for 30 minutes, the sections were incubated with primary antibodies against $\alpha$-SMA (Sigma-Aldrich), fibronectin (BD Biosciences, Los Angeles, California, USA), collagen III (Southern Biotechnology Associates, Birmingham, Alabama, USA), and laminin (Chemicon Inc., Temecula, California, USA), respectively, in PBS containing 1\% BSA overnight at $4^{\circ} \mathrm{C}$. Sections were then incubated for 1 hour with cyanine Cy3-conjugated, affinity-purified secondary antibodies (Jackson ImmunoResearch Laboratories Inc., West Grove, Pennsylvania, USA) at a dilution of 1:100 in PBS containing 1\% BSA, before being washed extensively with PBS. As a negative control, the primary antibody was replaced with nonimmune IgG, and no staining occurred. Some slides were then stained with proximal tubular marker, fluorescein-conjugated lectin from Tetragonolobus purpureas (Sigma-Aldrich), for localizing the proximal tubules. Slides were mounted with Vectashield anti-fade mounting media (Vector Laboratories Inc., Burlingame, California, USA) and viewed with an Eclipse E600 epifluorescence microscope equipped with a digital camera (Nikon Inc., Melville, New York, USA). For quantitation of TBM lesions in the obstructed kidneys of $t P A^{+/+}$and $t P A^{-/-}$mice, sections from kidney cortex of each mouse were double stained with laminin/tubular marker. The percentages of renal tubules that had one or more breaks in their TBM were counted in a blinded fashion in randomly chosen, nonoverlapping high-power $(\times 400)$ fields. The data were calculated based on individual values that were determined in ten fields per mouse ( $n=5$ mice per group).

Biochemical measurement of total kidney collagen content.

For quantitative measurement of collagen accumulation and deposition in the kidney, total tissue collagen content was determined by biochemical analysis of the hydroxyproline in the hydrolysates extracted from kidney samples. This assay is based on the observation that essentially all the hydroxyproline in animal tissues is found in collagen. Briefly, an accurately weighed portion of the obstructed kidney was homogenized in distilled $\mathrm{H}_{2} \mathrm{O}$. The homogenates were hydrolyzed in $10 \mathrm{~N} \mathrm{HCl}$ by incubation at $110^{\circ} \mathrm{C}$ for 18 hours. The hydrolysates were dried by speed vacuum centrifugation over 3-5 hours and redissolved in a buffer containing $0.2 \mathrm{M}$ citric acid, $0.2 \mathrm{M}$ glacial acetic acid, $0.4 \mathrm{M}$ sodium acetate, and 0.85 M sodium hydroxide, $\mathrm{pH}$ 6.0. Hydroxyproline concentrations in the hydrolysates were chemically measured according to techniques previously described $(24,25)$. Total collagen was calculated based on the assumption that collagen contains $12.7 \%$ hydroxyproline by weight. The results of total tissue collagen content were expressed as $\mu \mathrm{g}$ collagen per mg kidney weight.

Western immunoblot analysis. Kidney tissue extract was prepared in a buffer containing commercial protease inhibitor cocktail (Sigma-Aldrich) by the procedures described previously (26). After protein concentration was determined, the tissue lysate was mixed with an equal amount of $2 \times$ SDS sample buffer. Samples were heated at $100^{\circ} \mathrm{C}$ for 5-10 minutes before loading and then separated on precast $10 \%$ or $5 \%$ SDS-polyacrylamide gels (Bio-Rad Laboratories Inc.). After the proteins were electrotransferred to a nitrocellulose membrane (Amersham Life Sciences Inc., Arlington Heights, Illinois, USA), nonspecific binding to the membrane was blocked for 1 hour at room temperature with 5\% nonfat milk in TBS buffer $(20 \mathrm{mM}$ Tris- $\mathrm{HCl}, 150 \mathrm{mM}$ $\mathrm{NaCl}$, and $0.1 \%$ Tween 20 ). The membranes were incubated for 16 hours at $4^{\circ} \mathrm{C}$ with various primary antibodies in TBS buffer containing $5 \%$ milk at the dilutions specified by the manufacturers. The monoclonal $\alpha$-SMA antibody was purchased from Sigma-Aldrich. The antibodies against TGF- $\beta$ type I receptor and $\beta$-actin were purchased from Santa Cruz Biochemicals (Santa Cruz, California, USA). Binding of primary antibodies was followed by incubation for 1 hour at room temperature with the secondary horseradish peroxidase-conjugated IgG in 5\% nonfat milk. The signals were visualized by enhanced chemiluminescence (ECL; Amersham Life Sciences Inc.).

Determination of basement membrane integrity by bacterial translocation. TBM integrity was assessed by a simple barrier-based method established in our laboratory, as 
described elsewhere (20). This assay evaluates the structural and functional integrity of a reconstituted TBM by bacterial translocation using a two-compartment Boyden chamber with Transwell filters with pores (3 $\mu \mathrm{m}$ in diameter) (Corning-Costar Corp., Corning, New York, USA). Briefly, Matrigel (Becton, Dickinson and Co., Bedford, Massachusetts, USA), a solubilized basement membrane matrix, was added to the Transwell filters to form matrix gels at $37^{\circ} \mathrm{C}$ that mimic the in vivo TBM (27). Matrigel at a concentration of $22 \mu \mathrm{g} / \mathrm{cm}^{2}$ produced a matrix gel layer at $15 \mu \mathrm{m}$ thick, which represents a 100 -fold thickness of native TBM $(150 \mathrm{~nm})$ (28). Preliminary studies showed that Matrigel on Transwell filters maintains its structural integrity for more than 7 days at $37^{\circ} \mathrm{C}$ and completely blocks bacterial translocation through the gel (data not shown). For the assay, the Transwell filters with Matrigel were incubated with tissue homogenates (rich in MMP-9) from the obstructed kidneys of $t P A^{+/+}$and $t P A^{-/-}$mice at $37^{\circ} \mathrm{C}$ for 4 days. E. coli DH5 $\alpha$ (Life Technologies Inc., Grand Island, New York, USA) was grown in LB medium at $37^{\circ} \mathrm{C}$ overnight, and bacterial concentration was estimated by reading the $\mathrm{OD}$ at $600 \mathrm{~nm}$, where an OD value of 1 is equivalent to $10^{9}$ bacteria $/ \mathrm{ml}$. About $10^{8}$ bacteria in $100 \mu \mathrm{l}$ were added to the upper compartment of the Boyden chamber in a final volume of 400 $\mu \mathrm{l}$. Aliquots $(20 \mu \mathrm{l})$ were removed from the $1 \mathrm{ml}$ of media in the bottom compartment of the chamber every half hour for 2 hours. Dilutions from each aliquot were plated on LB agar plates and incubated at $37^{\circ} \mathrm{C}$ for 16 hours, after which colonies were counted. To ascertain the involvement of MMP-9 in destroying TBM integrity, a potent MMP-9 inhibitor (MMP inhibitor II; Calbiochem-Novabiochem Corp.) (23) was included in the kidney homogenates of $t P A^{++}$and $t P A^{-/-}$mice at a final concentration of $10 \mathrm{nM}$ during the incubation with Matrigel. The effects of MMP-9 inhibition on the reconstituted TBM integrity were evaluated by the bacterial translocation assay.

Determination of tissue TGF- $\beta 1$ levels by ELISA. For measurement of active TGF- $\beta 1$ protein levels in tissue, kidneys were homogenized in extraction buffer containing $20 \mathrm{mM}$ Tris- $\mathrm{HCl}$ at $\mathrm{pH} 7.5,2 \mathrm{M} \mathrm{NaCl}, 0.1 \%$ Tween-80, 1 mM EDTA, and $1 \mathrm{mM}$ PMSF, and the supernatant was recovered following centrifugation at $19,000 \mathrm{~g}$ for 20 minutes at $4{ }^{\circ} \mathrm{C}$. Kidney tissue TGF- $\beta 1$ levels were determined using a Quantikine TGF- $\beta 1$ ELISA kit in accordance with the protocol specified by the manufacturer (R\&D Systems Inc., Minneapolis, Minnesota, USA). This kit measures the abundance of active TGF- $\beta 1$ protein that binds to its soluble type II receptor, which is precoated on a microplate. The concentration of tissue TGF- $\beta 1$ in kidneys was expressed as $\mathrm{pg} / \mathrm{mg}$ total protein.

Cell culture and $t P A$ treatment. Normal rat renal interstitial fibroblast (NRK-49F) cells were obtained from American Type Culture Collection (Rockville, Maryland, USA). Human proximal tubular epithelial HKC cells (clone 8) were provided by L. Racusen of Johns Hopkins University (Baltimore, Maryland, USA). Cells were maintained in DMEM/Ham's F12 (1:1) supplemented with $10 \%$ FBS (Life Technologies Inc.). The cells were seeded on 12-well culture plates to $60-70 \%$ confluence in complete medium containing $10 \%$ FBS for 16 hours, and then changed to serum-free medium after washing twice with serum-free medium. Human single-chain tPA (Sigma-Aldrich) was dissolved in $1 \mathrm{M}$ potassium bicarbonate as stock solution and added to the cultures at concentrations ranging from $10^{-9} \mathrm{M}$ to $10^{-7} \mathrm{M}$ as indicated. For control experiments, the cells were incubated with vehicle. After the cells were incubated for various periods of time following addition of tPA, supernatants were collected for assessment of MMP-9 and MMP-2 production and secretion by gelatin zymographic analyses, as described above. All experiments were repeated three times.

RT-PCR amplifications. NRK-49F fibroblasts were treated without or with tPA for various periods of time at the concentrations indicated. Total RNA was extracted using an Ultraspec RNA isolation system according to the instructions specified by the manufacturer (Biotecx Laboratories Inc.). RNA samples were quantified by determination of ultraviolet absorbance at $260 \mathrm{~nm}$. The first strand of cDNA was synthesized using $2 \mu \mathrm{g}$ RNA in $20 \mu \mathrm{l}$ of reaction buffer by reverse transcription using AMV-RT (Promega Corp., Madison, Wisconsin, USA) and random primers at $42^{\circ} \mathrm{C}$ for 30 minutes. PCR was carried out using a standard PCR kit on 1- $\mu \mathrm{l}$ aliquots of cDNA and HotStarTaq polymerase (QIAGEN Inc., Valencia, California, USA) with specific primer pairs designed for rat MMP-9 and $\beta$-actin. PCR consisted of 35 cycles at $94^{\circ} \mathrm{C}$ for 1 minute, $55^{\circ} \mathrm{C}$ for 1 minute, and $72^{\circ} \mathrm{C}$ for 1 minute, followed by a final extension step at $72^{\circ} \mathrm{C}$ for 7 minutes. The PCR products were size fractionated on a $1.0 \%$ agarose gel and detected by ethidium bromide staining. No detectable signal was found in a parallel control tube without reverse transcriptase (data not shown). The sequence of primer pairs for rat MMP-9 was described previously (29), with forward 5'-CTCACCAGCGCCAGCCGACTTAT and reverse 5'-GGCACTGAGGAATGATCTAA primers. The sequence of primer pairs for $\beta$-actin was as follows: forward, 5'-TCAAGATCATTGCTCCTCCTGAGC; reverse, 5'-TGCTGTCACCTTCACCGTTCCAGT. To further confirm the validity of RT-PCR products, an internal oligonucleotide (5'-AGCTGGCAGAGGATTACCTG) corresponding to rat MMP-9 cDNA sequence was synthesized and used as a probe to detect MMP-9 by Southern blot analysis, according to standard protocols (30).

Statistical analysis. All data examined were expressed as mean \pm SEM. For Western blot analysis, quantitation was carried out by scanning and analyzing the intensity of the hybridization signals using the NIH Image program. Statistical analysis of the data was performed using SigmaStat software (Jandel Scientific Software, San Rafael, California, USA). Comparison between groups was made using one-way ANOVA followed by the Student-Newman-Keuls test. A $P$ value of less than 0.05 was considered statistically significant. 
a
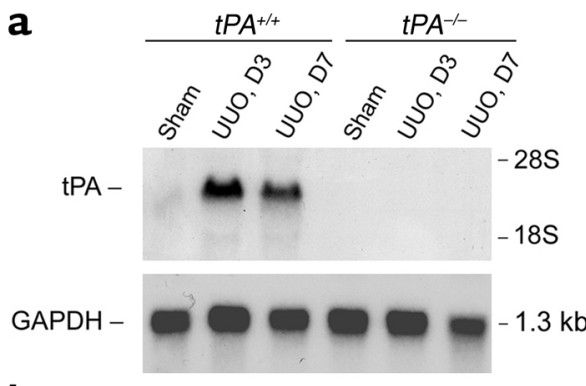

b
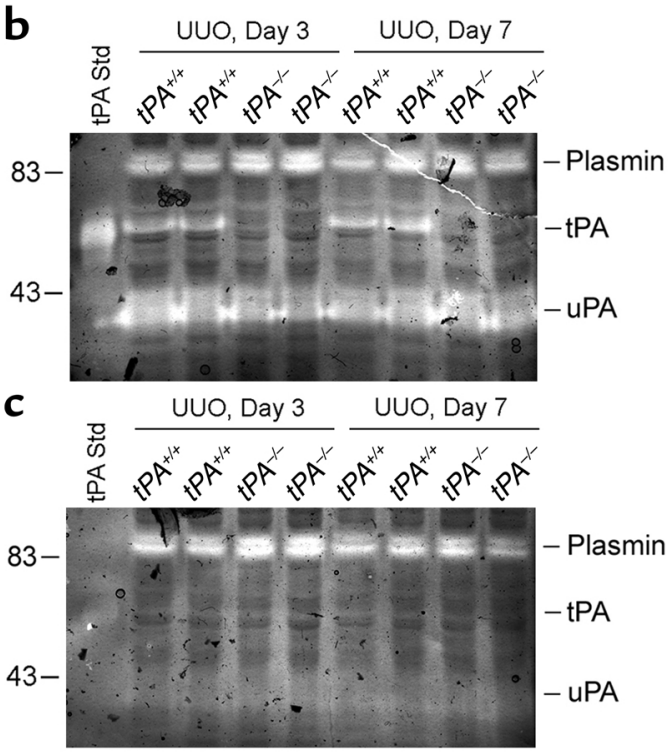

\section{Results}

Plasminogen activators and plasmin activities in the kidney of $t P A^{-1-}$ mutant mice. Age- and sex-matched wild-type $\left(t P A^{+/+}\right)$and knockout $\left(t P A^{-/-}\right)$mice were induced to develop renal interstitial fibrosis by UUO. The expression and activity of intrarenal $\mathrm{tPA}$ in $t P A^{+/+}$and $t P A^{-/-}$ mice was examined by both Northern blot analysis and casein zymography in the presence or absence of plasminogen. As shown in Figure 1a, ureteral obstruction induced a dramatic increase in $\mathrm{PA}$ mRNA expression in the kidney of wild-type mice. As expected, no tPA mRNA was detected in the kidneys of either sham-operated or obstructed $t P A^{-/-}$mice (Figure 1a). Likewise, no tPA activity was found in the kidney homogenates of $t P A^{-/-}$mice, whereas a clear band at about $54 \mathrm{kDa}$ was

\section{Figure 2}

Attenuation of renal morphological injury and interstitial matrix deposition in obstructive nephropathy in mice lacking tPA. Representative micrographs show kidney morphology ( $\mathbf{a}$ and $\mathbf{b}$ ), collagen III (c and $\mathbf{d}$ ), and fibronectin (e and $\mathbf{f}$ ) deposition at 7 days after ureteral obstruction in $t P A^{+/+}(\mathbf{a}, \mathbf{c}$, and $\mathbf{e})$ and $t P A^{--}(\mathbf{b}, \mathbf{d}$, and $\mathbf{f})$ mice. No appreciable difference in renal morphology and matrix deposition was observed in the kidneys of either sham-operated or UUO mice after 3 days between these two genotypes (not shown). However, significant reduction in morphological injury and interstitial matrix deposition was found at 7 days after UUO in the obstructed kidneys of $t P A^{-/-}$mice. The deposition of interstitial matrix components collagen III and fibronectin was shown by indirect immunofluorescence staining using specific antibodies. Scale bar, $20 \mu \mathrm{m}$.

\section{Figure 1}

Expression and activity of tPA in the kidney of $t P A^{+/+}$and $t P A^{-/-}$mice. (a) Northern blot analysis of tPA expression in the kidney of $t P A^{+/+}$ and $t P A^{-/-}$mice. Total RNA was isolated from the obstructed kidneys at day 3 and day 7 after UUO and hybridized with tPA cDNA probe. The same blot was stripped and reprobed with GAPDH to normalize the loading of each lane. The locations of $28 \mathrm{~S}$ and $18 \mathrm{~S}$ RNA are indicated. ( $\mathbf{b}$ and $\mathbf{c}$ ) Zymographic analysis of tPA activity in the kidney homogenates of $t P A^{+/+}$and $t P A^{-/-}$mice in the presence $(\mathbf{b})$ or absence (c) of plasminogen. Equal amounts of whole-kidney homogenates (30 $\mu$ g protein) from either $t P A^{+/+}$or $t P A^{-/-}$mice at day 3 and day 7 after UUO were loaded onto casein zymographic gel. A tPA standard (Std) was loaded in an adjacent lane to serve as positive control. The positions of tPA, UPA, and plasmin are indicated.

evident in the samples derived from wild-type counterparts (Figure 1b). The identification of this intrarenal tPA activity in the $t P A^{+/+}$mice was verified by including purified tPA protein in an adjacent lane as a positive control (Figure 1b). Furthermore, tPA and uPA activity completely disappeared when plasminogen was eliminated from the gel (Figure 1c). Incubation with aprotinin, a plasmin inhibitor, abolished all lytic clearing in the absence of plasminogen (not shown), verifying that the upper bands were contributed by plasmin.

As noted above, the UPA and plasmin activities were also evident in the casein zymographical gels. No difference in uPA activity was detected between $t P A^{+/+}$and $t P A^{-/-}$mice (Figure 1), suggesting that uPA is not upregulated to compensate for the loss of tPA in the knockout mice. Paradoxically, despite the absence of tPA, the activity of intrarenal plasmin in the knockout mice was not reduced; in fact, it was slightly increased at day 3 after UUO, compared with the wild-type controls (Figure 1).

Attenuation of renal interstitial fibrosis in obstructive nephropathy in $t P A^{-/-}$mice. Figure 2 shows representative micrographs of the obstructed kidneys in $t P A^{+/+}$
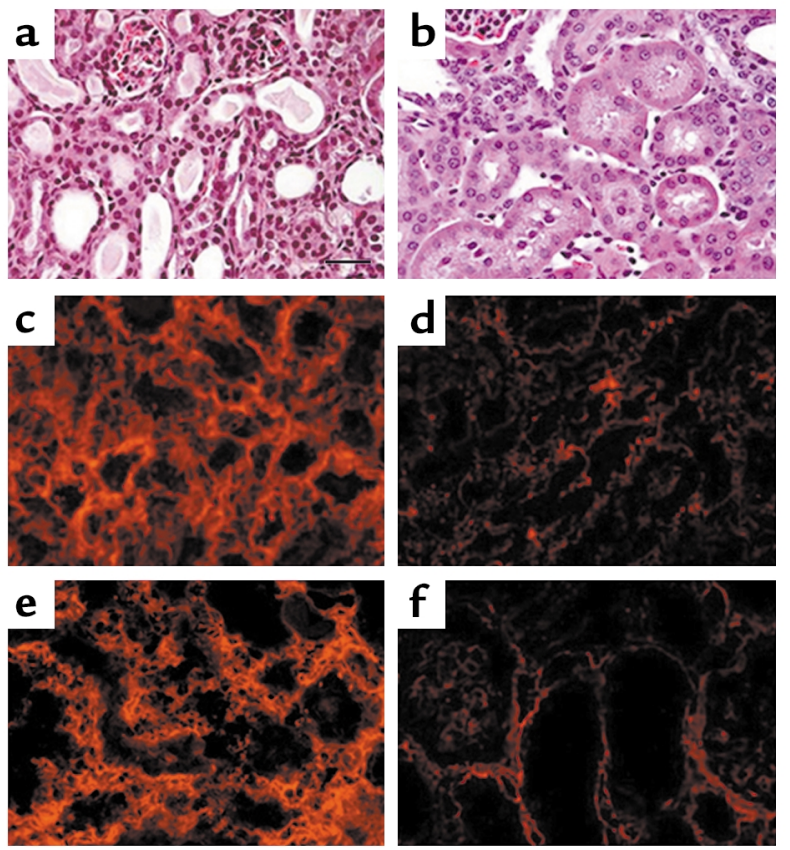


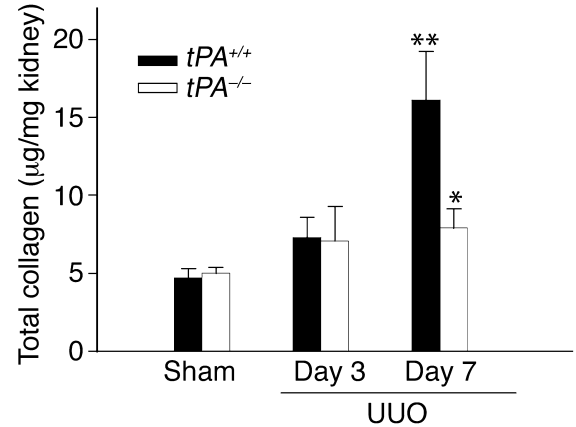

Figure 3

Disruption of tPA gene reduces total collagen accumulated in the obstructed kidney. Total kidney collagen content in the obstructed kidneys in sham-operated mice and at day 3 and day 7 after UUO in $t P A^{+/+}$and $t P A^{-/-}$mice was determined by biochemical assay. Results in various groups are expressed as $\mu$ g per mg kidney and presented as mean $\pm \operatorname{SEM}(n=5)$. ${ }^{*} P<0.01$ vs. all other groups. ${ }^{*} P<0.01$ vs. $t P A^{+/+}$mice.

and $t P A^{-/-}$mice at 7 days after surgery. To our surprise, disruption of the tPA gene resulted in less morphological injury to the obstructed kidneys than was seen in the wild-type. In $t P A^{+/+}$mice with sustained, complete ureteral obstruction for 7 days, kidneys developed severe morphological lesions characterized by tubular dilation with epithelial atrophy, interstitial expansion with hypercellularity resulting from myofibroblast activation, and extracellular matrix accumulation. Under the same conditions, renal pathology was significantly improved in mice lacking tPA (Figure 2), suggesting that endogenous tPA induces damage by promoting renal fibrotic lesions after chronic injury. Of note, no significant difference in the severity of renal pathology was found in $t P A^{-/}$ and $\mathrm{tPA}^{+/+}$mice at 3 days after obstruction (data not shown).

We further examined the deposition of interstitial matrix components in the obstructed kidneys in $t P A^{+/+}$and $t P A^{-/-}$mice. Consistent with the morphological lesions, less collagen III and fibronectin deposition was found in the kidney at 7 days after ureteral obstruction in the $t P A^{-/}$ mice (Figure 2) than in their wildtype controls. To quantitatively measure matrix accumulation, we determined the total tissue collagen content in the obstructed kidneys by a biochemical assay. Figure 3 shows the total kidney collagen content in the obstructed kidneys at day 3 and day 7 after surgery in $t P A^{+/+}$and $t P A^{-/-}$mice. No significant difference in total collagen content between $t P A^{+/+}$ and $t P A^{-1-}$ mice was found in the obstructed kidneys at day 3 (Figure 3). About threefold-higher levels of collagen deposition were observed in the obstructed kidneys compared with sham-operated controls at day 7 in $t P A^{+/+}$mice (Figure 3). However, deficiency of tPA dramatically inhibited collagen accumulation in the kidneys after the same period (7 days) of ureteral obstruction (Figure 3). In fact, the level of total collagen in the obstructed kidney at day 7 in $t P A^{-/-}$mice was compatible to that in sham-operated controls $(7.91 \pm 1.23$ vs. $4.98 \pm 1.16, P=0.858, n=5)$. Thus, disruption of the tPA gene protects kidney from developing interstitial fibrotic lesions after chronic, persistent injury.

Selective blockade of tubular epithelial-to-myofibroblast transition in $t P A^{-/}$mice after sustained ureteral obstruction. Because $\alpha$-SMA-positive myofibroblasts are the principal cells responsible for interstitial matrix accumulation and deposition, we next investigated the magnitude of myofibroblast activation after ureteral obstruction in $t P A^{+/+}$and $t P A^{-/-}$mice. As shown in Figure 4 , the level of $\alpha$-SMA protein in the kidneys at 7 days after ureteral obstruction in $t P A^{-/-}$mice was significantly lower than that in their wild-type controls. Quantitative determination of the Western blot of whole-kidney lysates revealed about $60 \%$ inhibition of
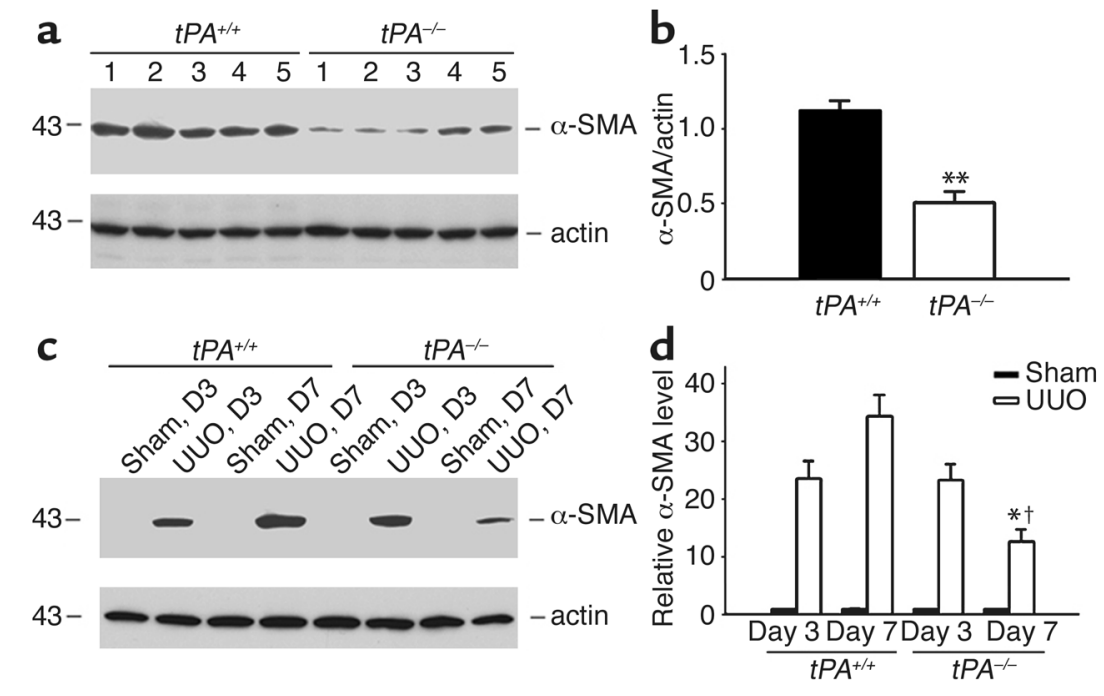

Figure 4

Reduced $\alpha$-SMA induction occurs at day 7 , but not day 3 , after UUO in mice lacking tPA. (a) Western blot shows $\alpha$-SMA expression in the obstructed kidney at day 7 after ureteral obstruction in $t P A^{+/+}$and $t P A^{-/-}$mice. The samples were reprobed with actin to confirm equal loading of each lane. Lanes 1-5 represent individual animals in each group. (b) Graphic presentation of relative $\alpha$-SMA abundance normalized to actin in $t P A^{+/+}$and $t P A^{-/-}$mice. ${ }^{* *} P<$ $0.05, n=5$. (c) Representative Western blot shows the time course of $\alpha$-SMA expression in the obstructed kidneys in $t P A^{+/+}$and $t P A^{-/-}$mice. Sham-operated and obstructed kidneys were collected at 3 days and 7 days after surgery. The kidney homogenates were probed with antibodies against $\alpha$-SMA and actin, respectively. (d) Graphic presentation of relative $\alpha$-SMA abundance (fold induction with levels in sham kidney as 1.0) normalized to actin in $t P A^{+/+}$ and $t P A^{-/-}$mice at different timepoints $(n=5) .{ }^{*} P<0.01, t P A^{+/+} v s . t P A^{-/-}$mice at day 7 after $\mathrm{UUO} ;{ }^{\dagger} P<0.05$, day 7 vs. day 3 after UUO in $t P A^{-/-}$mice. 
$\alpha$-SMA protein in $t P A^{-/-}$mice compared with the levels in $t P A^{+/+}$mice. Time-course studies exhibited that a significant difference in $\alpha$-SMA levels was observed only at a late stage (day 7) in obstructive nephropathy, a timepoint when tubular epithelial-to-myofibroblast transition is prominent in this model (20). No appreciable difference between the $t P A^{+/+}$and $t P A^{-/-}$mice was detected in renal $\alpha$-SMA expression at 3 days after ureteral obstruction (Figure 4, c and d). Interestingly, the $\alpha$-SMA level at 7 days after UUO was actually lower than that at 3 days in $t P A^{-/-}$mice (Figure 4, $\mathrm{c}$ and $\mathrm{d}$ ). A similar level of $\alpha$-SMA protein was detected in the sham-operated kidneys in $t \mathrm{PA}^{+/+}$and $t \mathrm{PA}^{-/-}$mice, suggesting that tPA deficiency did not alter $\alpha$-SMA expression under basal conditions.

We next examined myofibroblast activation in the obstructed kidneys in $t P A^{+/+}$and $t P A^{-/-}$mice by immunofluorescence staining. As shown in Figure 5, similar myofibroblast activation was found in $t P A^{+/+}$ and $t P A^{-/-}$mice at 3 days after obstruction. Double staining for $\alpha$-SMA (red) and proximal tubular marker (green) revealed that myofibroblast cells were predominantly localized within the interstitial compartment at this stage. At 7 days after UUO, marked activation of $\alpha$-SMA-positive myofibroblasts was observed in the $t \mathrm{PA}^{+/+}$mice (Figure 5g). There were abundant cells undergoing tubular epithelial-to-myofibroblast transition, as demonstrated by positive staining for both $\alpha$-SMA and proximal tubular marker (Figure 5i). Cells at the transitional stage (yellow) between tubular epithelia and myofibroblast were typically disorganized and estranged from their neighbors. In contrast, significantly fewer myofibroblasts were identified in the obstructed kidney of $t P A^{-/-}$mice at 7 days after surgery, and these were primarily confined to the interstitial compartment. In accordance with $\alpha$-SMA protein expression (Figure 4), less myofibroblast activation was observed at day 7 than at day 3 in the obstructed kidneys in $t P A^{-/-}$mice (Figure 5). These results suggest that null mutation of the tPA gene attenuates myofibroblast activation by selectively blocking tubular epithelial-to-myofibroblast transition in the diseased kidneys.

Induction of TGF- $\beta 1$ axis expression is not altered in the obstructed kidneys in $t P A^{-/-}$mice. Since TGF- $\beta 1$ is believed to play a critical role in initiating and promoting myofibroblast activation and fibrotic lesions in vivo $(5,20,31)$, we tested the hypothesis that altered TGF- $\beta 1$ expression may account for the difference in interstitial fibrosis after chronic injury in $t P A^{+/+}$and $t P A^{-/-}$ mice. TGF- $\beta 1$ protein levels were determined by ELISA of whole-kidney lysates. As demonstrated in Figure 6a, ureteral obstruction caused a marked increase in renal TGF- $\beta 1$ expression in the kidneys in a time-dependent manner. However, no significant difference in TGF- $\beta 1$ protein level was found in the obstructed kidneys in $t P A^{+/+}$and $t P A^{-/-}$mice at 3 days and 7 days after UUO, suggesting that the renal protection seen in $t P A^{-/}$ mice is not attributable to altered TGF- $\beta 1$ induction following persistent injury.

Levels of TGF- $\beta 1$ type I receptor were also examined by Western blot analysis of whole-kidney lysates in $t P A^{+/+}$ and $t P A^{-/-}$mice after ureteral obstruction. As shown in Figure $6 \mathrm{~b}$, the protein level of TGF- $\beta 1$ receptor type I was virtually identical between $t P A^{+/+}$and $t P A^{-/-}$mice in the obstructed kidneys at 7 days after UUO. Hence, expression of the TGF- $\beta 1$ axis does not account for the renal protection elicited by tPA deficiency in obstructive nephropathy. Similar levels of HGF expression were also observed in the obstructed kidneys of $t \mathrm{PA}^{+/+}$and $t \mathrm{PA}^{-/-}$ mice at 7 days (data not shown).

$M M P-9$ induction is markedly attenuated in $\mathrm{PA}^{-/-}$ mice after ureteral obstruction. We investigated the matrix-degrading proteases in the obstructed kidneys from $t P A^{+/+}$and $t P A^{-/-}$mice because a well-known
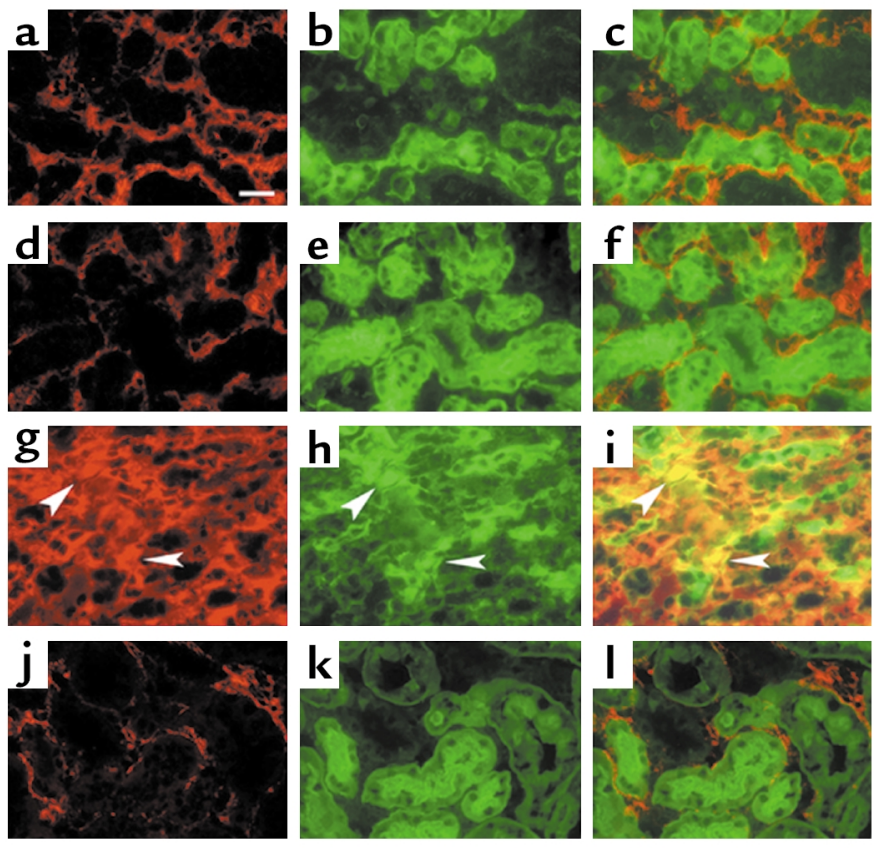

\section{Figure 5}

Deficiency of tPA selectively blocks the tubular epithelial-to-myofibroblast transition but not myofibroblastic activation from interstitial fibroblasts. Immunofluorescence staining demonstrates $\alpha$-SMA-positive myofibroblasts in the obstructed kidneys in $t P A^{+/+}$and $t P A^{-/-}$mice. Left column: staining with $\alpha$-SMA (red); middle column: staining with renal proximal tubule marker, fluorescein-conjugated lectin from $T$. purpureas (green); right column: merging of the two images. (a, $\mathbf{b}$, and $\mathbf{c}$ ) Images taken 3 days after $U \cup O$ in $t P A^{+/+}$mice. (d, e, and $\left.\mathbf{f}\right)$ Images taken 3 days after $U U O$ in $t P A^{-/-}$mice. (g, $\mathbf{h}$, and i) Images taken 7 days after $U U O$ in $t P A^{+/+}$mice. (j, $\mathbf{k}$, and I) Images taken 7 days after $U U O$ in $t P A^{-/-}$mice. No significant difference in the intensity and localization of $\alpha$-SMA-positive cells in the obstructed kidneys at day 3 after UUO was observed between $t P A^{+/+}$and $t P A^{-/-}$mice. Marked tubular epithelial-to-myofibroblast transition was evident in $t P A^{+/+}$mice at 7 days after ureteral obstruction, as demonstrated by colocalization of $\alpha$-SMA and tubular marker (yellow) (i). Myofibroblasts were reduced in number and limited to the interstitial compartment of the obstructed kidneys after 7 days in $t P A^{-/-}$mice (I). Scale bar, $20 \mu \mathrm{m}$. 
a
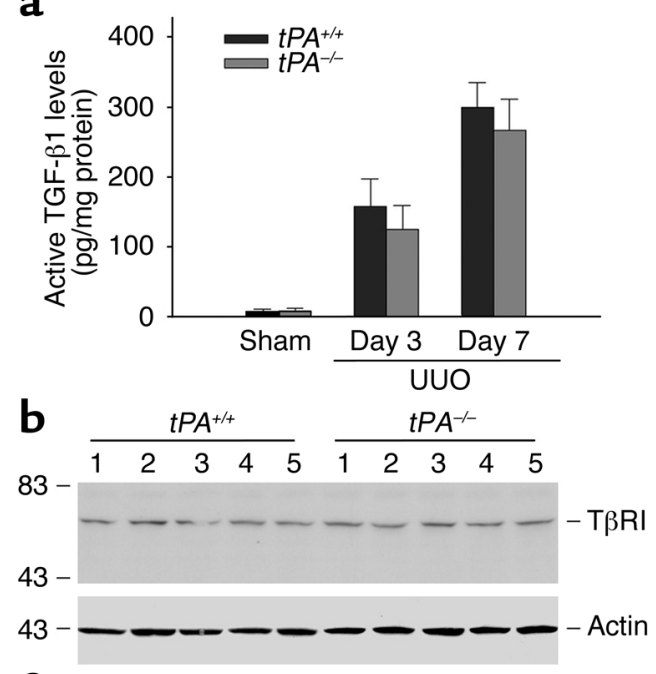

C

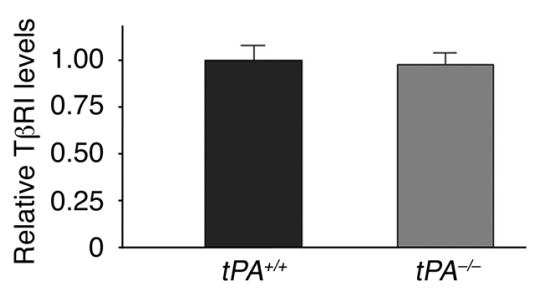

downstream function of tPA is regulating the activities of MMPs. Gelatin zymographic analysis of whole-kidney lysates displayed marked induction of both MMP-2 and MMP-9 in the obstructed kidneys of $t P A^{+/+}$ mice at 7 days after ureteral obstruction. However, compared with their wild-type controls, MMP-9 induction was dramatically attenuated in the obstructed kidneys from $t P A^{-/-}$mice (Figure 7). Both pro-MMP-9 and active MMP-9 levels in kidney lysates were markedly reduced in $t P A^{-/-}$mice at 7 days after UUO. Under the

\section{Figure 6}

Expression of TGF- $\beta 1$ axis is induced in a similar manner in the obstructed kidneys of $t P A^{+/+}$and $t P A^{-/-}$mice. (a) TGF- $\beta 1$ protein levels in the obstructed kidneys were determined by specific ELISAs at different timepoints in $t P A^{+/+}$and $t P A^{-/-}$mice. No significant difference in TGF- $\beta 1$ induction after ureteral obstruction was observed between $t P A^{+/+}$and $t P A^{-/-}$mice. Data are presented as mean \pm SEM $(n=5, P>0.05)$. (b) Western blot demonstrates TGF- $\beta$ type I receptor (T $\beta R 1)$ in the obstructed kidneys at day 7 after UUO. The same blot was reprobed with actin to confirm equal loading of each lane. Lanes 1-5 indicate individual animals in each group. (c) Graphic presentation of relative TGF- $\beta$ type I receptor abundance normalized to actin in $t P A^{+/+}$and $t P A^{-/-}$mice. Virtually identical levels of TGF- $\beta 1$ receptor type I protein were found in $t P A^{+/+}$and $t P A^{-/-}$mice after quantitative determination.

same conditions, intrarenal MMP-2 expression barely decreased in $t P A^{-/-}$mice compared with $t P A^{+/+}$controls. This result on MMP-2 expression in $t P A^{+/+}$and $t P A^{-/-}$ mice was further confirmed by Western blot analysis of whole-kidney lysates with anti-MMP-2 antibody (data not shown). Therefore, tPA deficiency results in dramatic attenuation of MMP-9 induction in obstructed kidneys after UUO.

The expression of MMP-9 was also examined by immunofluorescence staining. In the obstructed kidneys of $t P A^{+/+}$mice, abundant MMP-9 was largely expressed in the interstitial cells and confined to the TBM area and its close proximity (Figure 7). In some regions, tubular epithelial cells disaggregated and formed discontinuous, islanded cell clusters (Figure 7d), which presumably resulted from an apparent breakdown of TBM that normally confines tubular epithelia. Double staining with proximal tubular marker and MMP-9 antibody revealed that these tubular cell clusters were isolated and bathed in the background of overflowing MMP-9 (Figure 7e, asterisk).

\section{Figure 7}

Induction of MMP-9 is largely blunted after ureteral obstruction in $\mathrm{tPA}^{-/-}$mice. (a) Zymographic analysis of whole-tissue lysate of the obstructed kidneys at 7 days after $U \cup O$ in $t P A^{+/+}$and $t P A^{-/-}$mice. Samples equalized for protein content were separated on a polyacrylamide gel containing $1 \mathrm{mg} / \mathrm{ml}$ gelatin. Proteolytic activity was demonstrated by digestion of gelatin, resulting in the bands of clearing. The locations of bands corresponding to MMP-9 and MMP-2 are indicated. Representative pictures show the results of two animals per group. (b) Graphic presentation of the relative abundance of MMP-9 (both pro-MMP-9 and active MMP-9) in obstructed kidneys in $t P A^{+/+}$and $t P A^{-/-}$mice. Data are presented as mean \pm SEM of five animals per group $(n=5) .{ }^{*} P<0.01$, UUO vs. sham-operated. $¥ P<0.05$, $t P A^{+/+}$vs. $t P A^{-/-}$mice. (c-h) Immunofluorescence staining of MMP-9 protein in the obstructed kidneys at 7 days after $U \cup O$ in $t P A^{+/+}$and $t P A^{-/-}$mice (red). Renal proximal tubules were stained with lectin from $T$. purpureas (green). (c, d, and $\mathbf{e}) t P A^{+/+}$mice. $(\mathbf{f}, \mathbf{g}$, and $\mathbf{h})$ $t P A^{-/-}$mice. In $\mathbf{d}$ and $\mathbf{e}$, asterisk $\left({ }^{*}\right)$ indicates disaggregated, isolated tubular cell clusters on a background of abundant MMP-9 protein. Scale bar, $20 \mu \mathrm{m}$. a
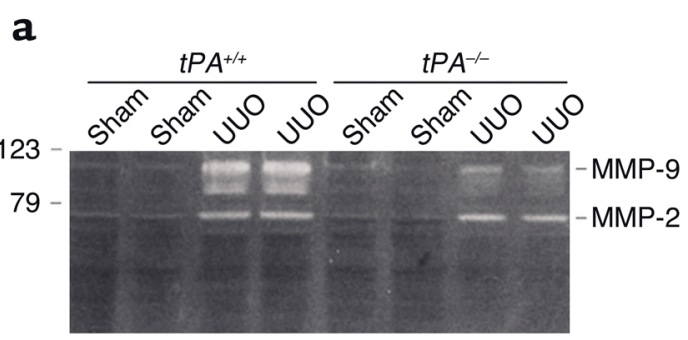

b
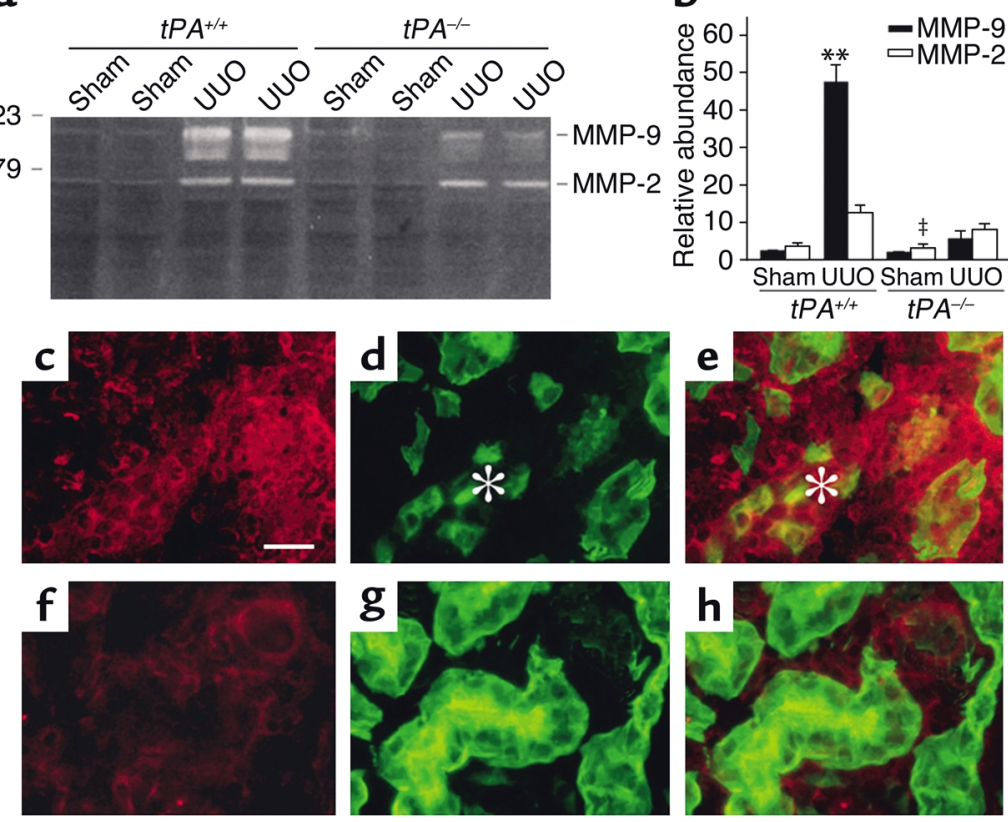
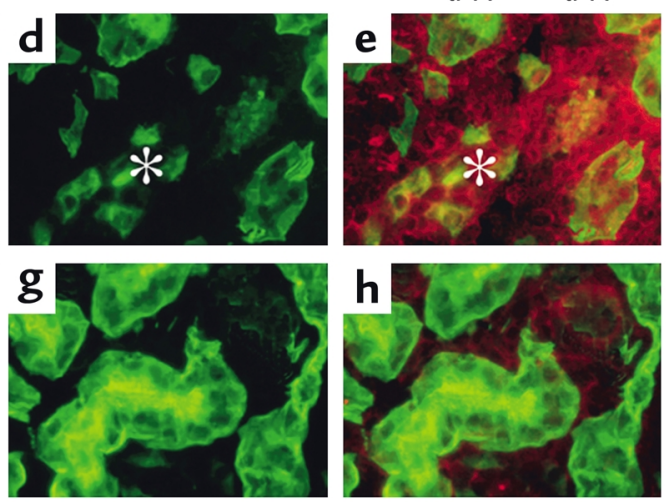

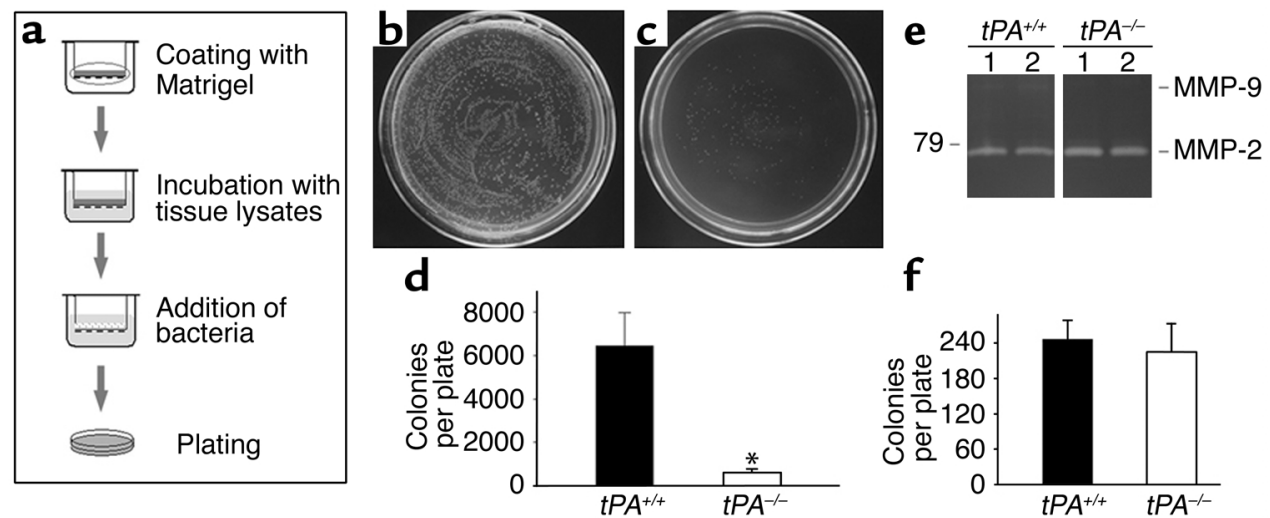

\section{Figure 8}

Deficiency of tPA preserves the functional integrity of TBM in the obstructed kidneys. TBM functional integrity was determined by bacterial translocation across the reconstituted TBM. (a) Schematic depiction of experimental procedures. Matrigels (15 $\mu \mathrm{m}$ thick) analogous to native TBM matrix were formed on Transwell filters and incubated with whole-tissue lysates of the obstructed kidneys collected 7 days after UUO from $t P A^{+/+}$and $t P A^{-/-}$mice. The integrity of the Matrigels was assessed by bacterial translocation through the gels. Representative plates show the colonies formed from the bacteria that passed through the Matrigels after incubation with tissue extracts from either $t P A^{+/+}$ (b) $\operatorname{or} t P A^{-/-}$(c) mice. (d) Graphic presentation of the numbers of bacteria translocated through the Matrigels $(n=5) .{ }^{*} P<0.01 \mathrm{vs} . t P A^{+/+}$ mice. (e) Zymographic analysis shows the specificity of MMP-9 inhibitor. Tissue lysates from the obstructed kidneys of either $t P A^{+/+}$or $t P A^{-/-}$ mice were separated on a polyacrylamide gel containing $1 \mathrm{mg} / \mathrm{ml}$ gelatin. A potent MMP-9 inhibitor (MMP inhibitor II) was included in the developing buffer at a concentration of $10 \mathrm{nM}$. The locations of bands corresponding to MMP-9 and MMP-2 are indicated. Numbered lanes indicate two animals per group. (f) Graphic presentation of the numbers of bacteria translocated through Matrigels preincubated with kidney lysates in the presence of $10 \mathrm{nM}$ MMP-9 inhibitor. No statistically significant difference was found between $t P A^{+/+}$and $t P A^{-/-}$groups.

However, much less MMP-9 staining was observed in the obstructed kidneys of $t P A^{-/-}$mice.

$T B M$ integrity is preserved in obstructed kidneys in $t P A^{-/}$ mice. Because one of the specific substrates for MMP-9 is collagen IV $(2,32,33)$, a major component of TBM, induction of MMP-9 could lead to destruction of renal TBM integrity, which is one of the key events during tubular epithelial-to-myofibroblast transition (20). To test this hypothesis, we investigated and compared the effects of kidney tissue lysates rich in MMP-9 on TBM integrity using a bacterial translocation assay. This assay takes advantage of the properties of Matrigel used as a reconstituted TBM (20). As shown in Figure 8, incuba- tion of Matrigel with kidney lysate from $t P A^{-/-}$mice at 7 days after UUO resulted in fewer bacteria translocated through the Matrigel than when lysate of $t P A^{+/+}$mice was used, suggesting that TBM integrity is well preserved in the kidney of $t P A^{-/-}$mice following ureteral obstruction. To ascertain the involvement of MMP-9, we examined the effects of specific MMP-9 inhibition on destruction of TBM integrity by kidney tissue lysates. As shown in Figure 8e, incubation with a potent MMP9 inhibitor at a concentration of $10 \mathrm{nM}$ almost completely abolished MMP-9 activity in the kidney lysates from $t P A^{+/+}$and $t P A^{-/-}$mice, as demonstrated by a gelatin zymographic assay. Under the same conditions,

\section{Figure 9}

TBM structural integrity is largely preserved in the obstructed kidneys in $t P A^{-/-}$mice. TBM structural integrity was examined by immunofluorescence staining of laminin, the major component of TBM. (a-e) Representative micrographs show the TBM (red) and tubular cells (green) in obstructed kidneys at 7 days after $U U O$ in $t P A^{+/+}(\mathbf{a}-\mathbf{c})$ and $t P A^{-/-}(\mathbf{d}$ and $\mathbf{e})$ mice. Renal proximal tubules were stained with lectin from T. purpureas (green). The TBM in the kidney of $t P A^{+/+}$mice is displayed as severely impaired, broken, and interrupted (arrowheads), whereas TBM structural integrity was largely preserved in $t P A^{-/-}$mice. Images in $\mathbf{b}$ and $\mathbf{c}$ are enlarged from the boxed areas in $\mathbf{a}$, and $\mathbf{e}$ is an enlargement of the boxed area in $\mathbf{d}$. Arrowheads indicate the broken TBM. Scale bar in $\mathbf{a}$ and d: $20 \mu \mathrm{m}$; scale bar in b, c, and e: $10 \mu \mathrm{m}$. (f) Graphic presentation of the percentages of renal tubules with TBM lesions in the cortical region of obstructed kidneys in $t P A^{+/+}$ and $t P A^{-/-}$mice. The data were calculated based on individual values determined on ten fields per mouse, five mice per group $(n=5) .{ }^{*} P<0.01$ vs. $t P A^{+/+}$mice.
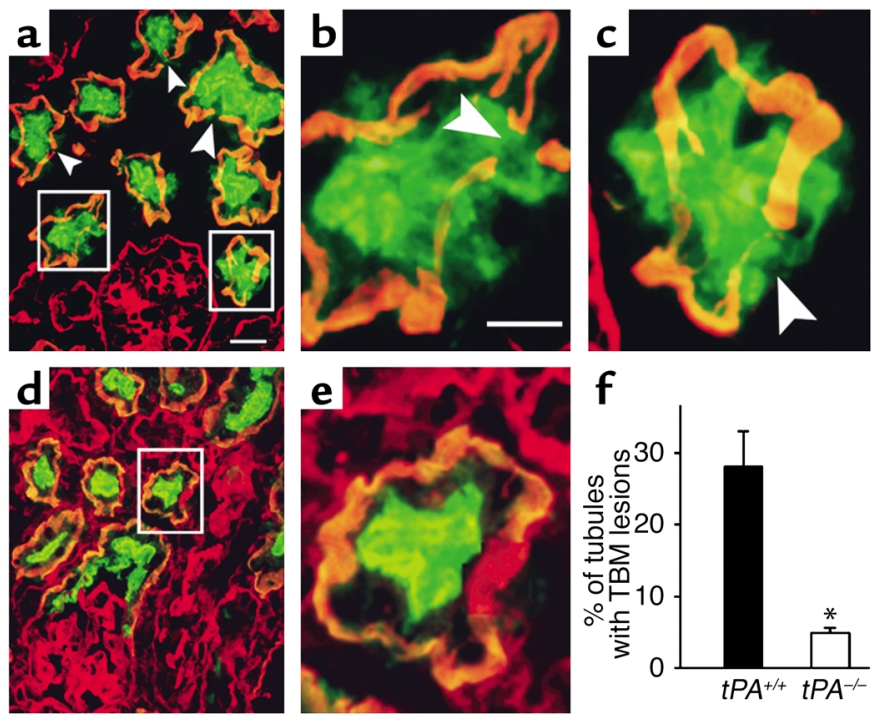


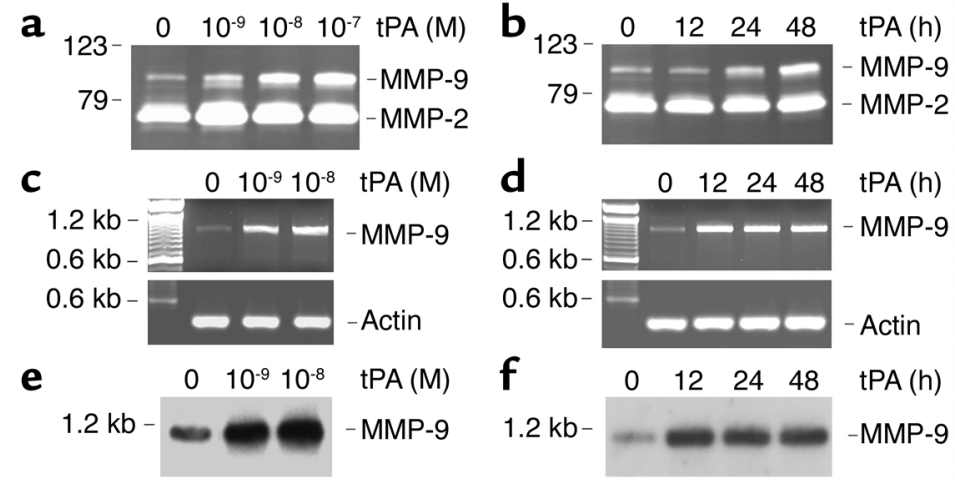

\section{Figure 10}

tPA induces MMP-9 protein secretion and gene expression in renal interstitial fibroblasts. ( $\mathbf{a}$ and $\mathbf{b}$ ) Zymographic analysis shows an induction of MMP-9 secretion by tPA. Rat renal interstitial fibroblasts (NRK-49F) were incubated with different concentrations $\left(10^{-9}\right.$ to $\left.10^{-7} \mathrm{M}\right)$ of human $\mathrm{tPA}$ protein for 48 hours $(\mathbf{a})$, or with $10^{-8} \mathrm{M}$ tPA for various periods of time $(\mathbf{b})$. Samples of the cell culture supernatants were separated on a polyacrylamide gel containing $1 \mathrm{mg} / \mathrm{ml}$ gelatin. Proteolytic activity was demonstrated by digestion of gelatin, resulting in the bands of clearing. The locations of bands corresponding to MMP-9 and MMP-2 are indicated. (c and d) RT-PCR analysis demonstrates that tPA induces MMP-9 gene expression in renal interstitial fibroblasts. NRK-49F cells were incubated with different concentrations $\left(10^{-9}\right.$ and $\left.10^{-8} \mathrm{M}\right)$ of human tPA protein for 24 hours $(\mathbf{c})$, or with $10^{-8} \mathrm{M}$ tPA for various periods of time (d). Cellular MMP-9 mRNA levels were determined by RT-PCR analysis. Amplified MMP-9 cDNA fragment with the correct size $(1.16 \mathrm{~kb})$ is indicated. RT-PCR amplification of housekeeping $\beta$-actin was performed in an identical manner to serve as control. (e and $\mathbf{f}$ ) Southern blot analysis of the RT-PCR product. To confirm the RT-PCR product as MMP-9 cDNA, Southern blot analysis of the RT-PCR product in $\mathbf{c}$ and $\mathbf{d}$ was performed using an internal oligonucleotide corresponding to MMP-9 cDNA as a probe.

MMP-2 activity was completely intact (Figure 8e), confirming the specificity of this MMP-9 inhibitor. When the MMP-9 inhibitor was included during the incubation of kidney lysates with Matrigel in the bacterial translocation assay, no significant difference was found in the numbers of bacteria translocated through Matrigel between $t P A^{+/+}$and $t P A^{-/-}$groups (Figure $8 \mathrm{f}$ ). Thus, preservation of TBM integrity in $t P A^{-/-}$kidneys is primarily mediated by reduced MMP-9 expression.

We further directly examined the TBM structural integrity of the obstructed kidney in $t P A^{+/+}$and $t P A^{-/-}$ mice. Immunofluorescence staining with laminin revealed a broken, discontinuous TBM in significant numbers of renal tubules from the kidneys of $t P A^{+/+}$ mice at 7 days after UUO (Figure 9, a-c). In the tubules with interrupted TBM, tubular epithelial cells tended to migrate toward the interstitial compartment (Figure 9, b and c). However, under identical conditions, TBM integrity was largely preserved with uninterrupted staining of TBM in $t \mathrm{PA}^{-/-}$mice (Figure $9, \mathrm{~d}$ and e). Quantitative determination revealed that about $28 \%$ of renal tubules in the cortical regions displayed TBM lesions manifested by one or more breaks in the kidneys of $t P A^{+/+}$mice at 7 days after UUO, whereas less than $5 \%$ of renal tubules had similar TBM lesions in $t P A^{-/-}$kidneys (Figure 9f). These results suggest that deficiency of tPA leads to decreased MMP-9 expression, which in turn preserves TBM from destruction under chronically pathologic conditions.

tPA induces MMP- 9 expression and secretion in renal interstitial fibroblasts in vitro. The fact that tPA deficiency leads to reduced MMP-9 expression in a plasmin-independent manner after renal injury raised the intriguing possibility that tPA might directly influence MMP-9 expression and secretion. To address this issue and to provide a mechanistic insight into the intrinsic connection between TPA and MMP-9, we investigated the effects of tPA on MMP-9 expression and secretion using an in vitro renal cell culture system. As shown in Figure 10, incubation of NRK-49F renal interstitial fibroblast cells with human tPA protein induced MMP-9 protein expression and secretion in a dose- and time-dependent manner. Zymographic analysis revealed that MMP-9 was markedly induced in the supernatant of NRK-49F fibroblasts when incubated with $10^{-7} \mathrm{M}$ tPA (Figure 10a). The MMP-9 induced by tPA at higher concentrations $\left(10^{-7}\right.$ and $\left.10^{-8} \mathrm{M}\right)$ was predominantly in zymogen form, implying that the robust MMP-9 is likely due to increased production rather than enhanced posttranslational activation. However, when tPA was used at a low concentration $\left(10^{-9}\right.$ $\mathrm{M})$, increased active MMP-9 was also evident in the supernatant of renal fibroblasts (Figure 10a). Of note, tPA did not significantly induce MMP-2 expression and secretion in these cells (Figure 10a). Incubation of human proximal tubular cells (HKCs) with tPA also did not induce MMP-9 expression and secretion (data not shown), consistent with the in vivo observation that MMP-9 did not colocalize with tubular marker in the obstructed kidneys (Figure 7e).

Given the induction of pro-MMP-9, but not active MMP-9, by tPA at higher concentrations, we suspected that tPA might activate MMP-9 gene expression, which in turn leads to increased MMP-9 protein secretion in renal interstitial fibroblasts. To prove this, we examined the steady-state levels of MMP-9 gene transcripts in NRK-49F cells after treatment with tPA. As demonstrated in Figure 10, c-f, a low level of MMP-9 mRNA was detected in NRK-49F cells under basal conditions as assessed by RT-PCR; however, tPA markedly induced MMP-9 gene transcripts in renal interstitial fibroblasts in a dose-dependent manner. Kinetics studies revealed that tPA stimulated MMP-9 gene expression as early as 12 hours after treatment, a timepoint significantly preceding induced MMP-9 protein secretion (24 hours). With these results taken together, it appears clear that tPA, a serine protease in nature, induces MMP-9 gene expression and protein secretion in renal interstitial fibroblast cells. 


\section{Discussion}

In view of its matrix-degrading capacity, tPA was originally hypothesized to be beneficial in chronic renal fibrogenesis due to its perceived potential to lessen interstitial matrix accumulation and deposition. Instead, in this report, we present evidence that the null mutation of the tPA gene protects kidney from developing interstitial fibrotic lesions after sustained ureteral obstruction, suggesting that endogenous tPA actually accelerates renal fibrogenesis. In this regard, our results using $t P A^{-/-}$mice are quite unanticipated. This beneficial outcome of tPA deficiency is likely attributable to a decrease in MMP-9 induction in these mice after chronic injury that in turn leads to preservation of the TBM and avoidance of tubular epithelial-tomyofibroblast transition as seen in wild-type kidneys. These data underscore that TBM integrity may play a fundamental role in prevention of tubular EMT, thereby attenuating renal interstitial fibrosis.

TBM integrity: a critical determinant for epithelial-to-myofibroblast transition in vivo. TBM consists predominantly of collagen IV, laminin, and entactin. It provides a structural foundation for tubular epithelial cells to lie upon for proper function. Growing evidence suggests that TBM is not just a static physical barrier that separates tubular epithelial and interstitial compartments in the kidney. Rather, its composition is dynamic in nature and it likely plays an important role in regulating tubular epithelial cell phenotype and physiology. For example, a recent report by Zeisberg et al. shows that alteration in TBM composition regulates tubular epithelial cell transdifferentiation in vitro (34). It is also reported that interstitial collagen type I tends to promote EMT, whereas the TBM component collagen type IV is likely to inhibit this phenotypic transition $(14,34)$. We previously demonstrated that EMT is an orchestrated, highly regulated process consisting of four key steps, in which destruction of the TBM plays a crucial role by clearing the path for transformed cells to ultimately migrate into the interstitial compartment of the kidney (20). The present study using $t P A^{-/}$mice implies that TBM integrity may have a greater role in EMT than we originally anticipated. Preservation of TBM integrity in $t P A^{-/}$mice not only leads to fewer myofibroblast cells in renal interstitium, which is presumably due to restraint of cell migration by the TBM barrier, but also reduces overall $\alpha$-SMA expression and myofibroblast activation in the obstructed kidneys. This suggests that TBM integrity per se may have the ability to block myofibroblastic transdifferentiation from tubular epithelia in vivo, probably by preventing the ready access of tubular epithelial cells to the interstitial matrix microenvironment after destruction of TBM (35). This view is in harmony with the notion that interstitial matrix components such as collagen type I and fibronectin, via their cellular receptor integrins, play a significant role in myofibroblastic transdifferentiation of renal tubules (36). Hence, TBM integrity is likely to be one of the pivotal determinant factors in regulating tubular epithelial cell phenotypic transition under pathologic conditions.
Renal EMT and interstitial fibrosis are regulated by several growth factors (17, 37-39). Profibrogenic TGF- $\beta 1$ initiates and completes the entire EMT course in cultured tubular epithelial cells in vitro $(13,20,40)$. Renal tubular cells incubated with TGF- $\beta 1$ lose the epithelial marker E-cadherin, induce de novo expression of $\alpha$-SMA, and reorganize actin to form stress fibers $(13,20)$. These cells also express abundant MMP-2, which can specifically degrade TBM, and acquire an enhanced motility and invasive capacity (20). In contrast, HGF has a remarkable ability to block tubular EMT initiated by TGF- $\beta 1$ both in vitro and in vivo (37). Given the fact that tPA is implicated in the posttranslational activation of TGF- $\beta 1$ (via plasmin) and HGF (directly), it is logical to speculate that altered TGF- $\beta 1$ and/or HGF expression and activation may account for amelioration of obstructive nephropathy in $t P A^{-/-}$mice. Upon examination, TGF- $\beta 1$ induction and activity in the obstructed kidneys were found to be similar in mice either retaining or lacking tPA (Figure $6)$, suggesting that any role for tPA in TGF- $\beta 1$ activation is compensated for by another mechanism in $t P A^{-/-}$mice. Consistent with this notion, little difference in the expression of MMP-2, one of the targets of TGF- $\beta 1$ signaling in tubular epithelial cells (20), was observed in the obstructed kidneys in the $t P A^{+/+}$and $t P A^{-/}$mice (Figure 7). Similarly, HGF activation in the obstructed kidneys was not significantly affected by the null mutation of tPA in the whole animal, despite its implication in HGF activation in vitro (4). This is not surprising, as the activation of HGF can be mediated by at least six serine proteases, including tPA, uPA, and HGF activator (4, 41-43). Hence, the functional redundancy of many factors in activating endogenous HGF may explain the similarity in HGF activation in obstructed kidneys from $t P A^{+/+}$and $t P A^{-/-}$mice. Furthermore, if tPA were of vital importance for HGF activation in vivo, one would expect to see more severe fibrotic lesions in $t \mathrm{PA}^{-/-}$mice, rather than less severe, because less anti-fibrogenic HGF activity would be expected in the kidneys of these mice after ureteral obstruction. Collectively, it is concluded that the attenuation of renal myofibroblast activation and interstitial fibrosis in $t P A^{-/-}$mice appears to be independent of TGF- $\beta 1$ and HGF. Thus, preservation of TBM integrity alone has major implications in preventing EMT and renal interstitial fibrosis at the whole-animal level.

Myofibroblast activation: diverse origins and distinct dynamics. Activated, $\alpha$-SMA-positive myofibroblasts are the principal matrix-producing cells responsible for excess interstitial extracellular matrix accumulation and deposition as seen in diseased kidneys. Myofibroblast activation arguably is a key event that precedes massive renal interstitial fibrosis. Because of their virtual absence in the interstitium of normal kidneys, the exact origin(s) and activation process of interstitial myofibroblasts under pathologic conditions remain largely undefined and controversial. Possible sources of renal myofibroblasts include interstitial 
fibroblasts, transdifferentiated tubular epithelial cells, and circulating mesenchymal precursor cells $(19,37)$. Whether only one or all of these potential sources contributes to the myofibroblast pool in a given disease condition remains elusive. The results from this study may shed new light on understanding the origins and dynamics of interstitial myofibroblast activation. It is tempting to propose that myofibroblast activation in the obstructive kidney is a dynamic process in which myofibroblasts are derived from local activation of residential fibroblasts at the earlier stage of obstructive nephropathy ( 3 days after obstruction) and are mainly derived from tubular epithelial cells via EMT at the later stage (7 days). Myofibroblast activation at the early stage ( 3 days) is confined to the interstitial compartment, and is likely independent of TBM integrity and EMT. However, in the later stage (7 days), myofibroblast activation originates mainly from EMT, which in turn relies on compromised TBM integrity (35). Thus, selective blockade of EMT at this phase in $t P A^{-/-}$mice as seen in the present study has major implications in myofibroblast accumulation in the obstructed kidneys. The observation that marked reduction of myofibroblasts occurs only at 7 days and not at 3 days after UUO in $t P A^{-/-}$mice strengthens this view. Furthermore, earlier studies in diverse animal models indicate that renal EMT typically takes place at the later stage during the pathogenesis of renal fibrosis $(16,19,20)$. Hence, it is highly likely that both interstitial fibroblasts and tubular epithelial cells contribute to the accumulation of myofibroblast cells at different phases in diseased kidneys.

If both interstitial fibroblasts and tubular epithelial cells contribute to the myofibroblast pool in diseased kidney, the fundamental question then is: what is the relative importance of EMT to renal fibrogenesis? In other words, is EMT essential for renal fibrogenesis? The difficulty in addressing this issue is obvious, because one cannot separate the myofibroblasts derived from EMT versus those derived from fibroblasts in vivo. In this regard, the finding on selective blockade of EMT, but not myofibroblast activation from fibroblasts, in obstructive nephropathy in $t P A^{-/-}$ mice suggests a unique model system for understanding the role of EMT in the pathogenesis of renal fibrosis. One of the intriguing findings in this study is that myofibroblast accumulation after sustained obstruction for 7 days was actually less than at 3 days in $t P A^{-/-}$ mice (Figure 4 and Figure 5). This suggests that in the absence of EMT, due to a selective blockade in $t P A^{-/-}$ mice, the progression of myofibroblast accumulation and renal interstitial fibrogenesis is not only blunted, but also reversed. This observation is of major importance, because for the first time it provides compelling evidence for a definite role of EMT in the pathogenesis of renal interstitial fibrosis in vivo. It now appears clear that without EMT, renal myofibroblast activation and interstitial fibrogenesis cannot be sustained and is likely to be reversible. This view is supported by earlier studies using the reversible UUO model. Relief of ureteral obstruction after 3 days restores renal structure and function (data not shown). Such short-term obstruction does not induce TBM destruction and EMT (Figure 5). However, renal structure and function is permanently impaired when relief of obstruction occurs after a sustained injury (more than 5 days) (44-46), a time when TBM integrity is impaired and EMT is prominent. Hence, EMT not only actively participates in the pathogenesis of interstitial fibrogenesis, but also may function as an intrinsic determinant for irreversible progression of chronic fibrotic lesions.

tPA and MMP-9: intrinsic connection beyond proteolytic cleavage. Among many of the growth factors and members of the plasminogen-plasmin and MMP systems studied, disruption of the tPA gene only attenuated MMP-9 induction in the diseased kidneys. This suggests an intrinsic link between tPA and MMP-9 in obstructive nephropathy. Surprisingly, ablation of tPA did not significantly affect the expression of either plasmin (a product of tPA) or uPA, the functional cousin of tPA that can also generate plasmin (Figure 1). Logically, loss of tPA would have been expected to result in an attenuation of plasmin activity or a compensatory increase in uPA. A reasonable explanation for these results is the existence of functional compensation and redundancy for tPA in vivo. Such functional compensation for knockout genes is not an unusual phenomenon (47-49).

MMP-9 and tPA are linked via classic proteolytic cleavage. It is well known that tPA can increase MMP9 activity by generating plasmin, which converts the zymogen into its active form. Surprisingly, the present study provides clear evidence that tPA is an upstream inducer for MMP-9 gene expression in the diseased kidney. Direct correlation between tPA and MMP-9 is established both by concomitant induction of tPA and MMP-9 expression in obstructed kidney in wild-type mice (Figure 1 and Figure 7) and by decreased expression of MMP-9 in the obstructed kidneys of $t P A^{-/-}$mice. More importantly, incubation of renal interstitial fibroblasts with tPA protein induced MMP-9 gene expression and protein secretion (Figure 10). These findings suggest that the connection between tPA and MMP-9 goes beyond proteolytic cleavage and involves MMP-9 gene activation by tPA. Of note, although sustained injury after ureteral obstruction induces both MMP-9 and MMP-2 in the kidney, earlier studies using cultured tubular epithelial cells indicate that TGF- $\beta 1$ is most likely responsible for MMP-2 induction (20). Any contribution of TGF- $\beta 1$ to MMP-9 induction is minimal during pathologic conditions (20).

How tPA controls MMP-9 gene expression in the diseased kidney remains a fascinating question. Our results suggest that tPA upregulates MMP-9 gene expression in vivo through a mechanism that is independent of its proteolytic activity, since plasmin activity was not reduced in $t P A^{-/-}$mice. Therefore, the intrinsic connection between tPA and MMP-9 may operate at 
two levels: plasmin-dependent MMP-9 posttranslational activation (classical) and plasmin-independent upregulation of MMP-9 gene expression (novel). Along this line, it is of interest to note that tPA at low concentration $\left(10^{-9} \mathrm{M}\right)$ increased active MMP-9 in renal interstitial fibroblasts, whereas at high concentrations $\left(10^{-8} \mathrm{M}\right.$ and $\left.10^{-7} \mathrm{M}\right)$ it predominantly induced proMMP-9, presumably by activating its gene expression (Figure 10). This implies that the dual actions of tPA are probably controlled by its concentration gradients in a given circumstance. In the pathophysiological states in which its level is high, tPA may activate MMP-9 primarily by upregulating its gene expression. Of note, such a high concentration of tPA $\left(10^{-8} \mathrm{M}\right)$ could be readily achievable under pathologic conditions, given the dramatic induction of its mRNA in the obstructed kidneys of $t P A^{+/+}$mice (Figure 1).

Our novel finding on the induction of MMP-9 gene expression by tPA suggests that this serine protease may have much broader functions in the diseased kidney than we originally thought. Although not tested, we would not be surprised if the expression of other genes besides MMP-9 could also be regulated by tPA. Consistent with this view, there are numerous studies demonstrating that components of the plasminogenplasmin and MMP systems, such as tPA, uPA receptor, PAI-1, and TIMP-1, elicit a wide range of cellular activities by initiating specific gene expression in ways other than their conventional function in the proteolytic cascade (50-56). In particular, tPA has been reported to stimulate PAI-1 secretion in human lung fibroblasts (57) and in rat epithelioid-type smooth muscle cells (58), although it remains unknown whether this action of tPA is mediated by inducing PAI-1 gene expression. It has also been shown that tPA is capable of mediating microglial activation in response to neuronal injury in a plasminogen-independent fashion $(59,60)$. In view of its ability to induce MMP-9 gene expression, it is plausible to speculate that tPA may function as a nonproteolytic cytokine that triggers a cascade of intracellular signal transduction, leading to expression of specific genes. Along this line, it is interesting to point out that tPA shares significant sequence and structure homology with two well-studied cytokines, HGF and macrophage-stimulating protein $(61,62)$.

In summary, the studies presented in this paper demonstrate that deficiency of tPA protects the kidney from developing fibrotic lesions in obstructive nephropathy. This beneficial effect is likely mediated by a cascade of events that include reduction of MMP9 expression, preservation of TBM integrity, and selective blockade of tubular EMT. In addition, we have uncovered a novel mechanistic link between tPA and MMP-9 in which the serine protease tPA activates MMP-9 gene expression and protein secretion. We show here that without significant alteration of major pro- and anti-fibrogenic growth factors (TGF- $\beta 1$ and HGF), and without affecting myofibroblastic activation from interstitial fibroblasts, selective blockade of tubular EMT alone in $t P A^{-/-}$kidneys dramatically ameliorates renal interstitial fibrosis after obstructive injury. Our results establish a vital role and definite contribution of EMT in renal interstitial fibrogenesis at the whole-animal level. Hence, blockage of any one of the key steps in EMT $(20,37)$ will offer unique opportunities for inhibiting myofibroblast activation from tubular epithelial cells and for ultimately mitigating renal interstitial fibrosis.

\section{Acknowledgments}

This work was supported by NIH grants DK-02611, DK-54922, and DK-61408 (to Y. Liu). J. Yang and C. Dai were supported by postdoctoral fellowships from the American Heart Association Pennsylvania-Delaware Affiliate. R.W. Shultz was a Summer Undergraduate Research Program Fellow in the Department of Pathology at the University of Pittsburgh School of Medicine.

1. Eddy, A.A. 2000. Molecular basis of renal fibrosis. Pediatr. Nephrol. 15:290-301.

2. Lenz, O., Elliot, S.J., and Stetler-Stevenson, W.G. 2000. Matrix metalloproteinases in renal development and disease. J. Am. Soc. Nephrol. 11:574-581.

3. Yee, J.A., Yan, L., Dominguez, J.C., Allan, E.H., and Martin, T.J. 1993. Plasminogen-dependent activation of latent transforming growth factor beta (TGF beta) by growing cultures of osteoblast-like cells. J. Cell. Physiol. 157:528-534.

4. Mars, W.M., Zarnegar, R., and Michalopoulos, G.K. 1993. Activation of hepatocyte growth factor by the plasminogen activators uPA and tPA. Am. J. Pathol. 143:949-958.

5. Border, W.A., and Noble, N.A. 1997. TGF-beta in kidney fibrosis: a target for gene therapy. Kidney Int. 51:1388-1396.

6. Matsumoto, K., and Nakamura, T. 2001. Hepatocyte growth factor: renotropic role and potential therapeutics for renal diseases. Kidney Int. 59:2023-2038.

7. Liu, Y. 2002. Hepatocyte growth factor and the kidney. Curr. Opin. Nephrol. Hypertens. 11:23-30.

8. Port, F.K., Fenton, S.S.A., and Mazzuchi, N. 2000. ESRD throughout the world: morbidity, mortality, and quality of life. Kidney Int. 57:S1-S2.

9. Essawy, M., et al. 1997. Myofibroblasts and the progression of diabetic nephropathy. Nephrol. Dial. Transplant. 12:43-50.

10. Roberts, I.S., Burrows, C., Shanks, J.H., Venning, M., and McWilliam, L.J. 1997. Interstitial myofibroblasts: predictors of progression in membranous nephropathy. J. Clin. Pathol. 50:123-127.

11. Powell, D.W., et al. 1999. Myofibroblasts. I. Paracrine cells important in health and disease. Am. J. Physiol. 277:C1-C9.

12. Liu, Y., Rajur, K., Tolbert, E., and Dworkin, L.D. 2000. Endogenous hepatocyte growth factor ameliorates chronic renal injury by activating matrix degradation pathways. Kidney Int. 58:2028-2043.

13. Fan, J.M., et al. 1999. Transforming growth factor-beta regulates tubular epithelial-myofibroblast transdifferentiation in vitro. Kidney Int. 56:1455-1467.

14. Okada, H., Danoff, T.M., Kalluri, R., and Neilson, E.G. 1997. Early role of Fsp1 in epithelial-mesenchymal transformation. Am. J. Physiol. 273:F563-F574.

15. Strutz, F., et al. 1995. Identification and characterization of a fibroblast marker: FSP1. J. Cell Biol. 130:393-405.

16. Ng, Y.Y., et al. 1998. Tubular epithelial-myofibroblast transdifferentiation in progressive tubulointerstitial fibrosis in $5 / 6$ nephrectomized rats. Kidney Int. 54:864-876.

17. Stahl, P.J., and Felsen, D. 2001. Transforming growth factor-beta, basement membrane, and epithelial-mesenchymal transdifferentiation: implications for fibrosis in kidney disease. Am. J. Pathol. 159:1187-1192.

18. Strutz, F., et al. 2002. Role of basic fibroblast growth factor- 2 in epithelial-mesenchymal transformation. Kidney Int. 61:1714-1728.

19. Iwano, M., et al. 2002. Evidence that fibroblasts derive from epithelium during tissue fibrosis. J. Clin. Invest. 110:341-350. doi:10.1172/JCI200215518.

20. Yang, J., and Liu, Y. 2001. Dissection of key events in tubular epithelial to myofibroblast transition and its implications in renal interstitial fibrosis. Am. J. Pathol. 159:1465-1475.

21. Yang, J., Dai, C., and Liu, Y. 2001. Systemic administration of naked plasmid encoding hepatocyte growth factor ameliorates chronic renal fibrosis in mice. Gene Ther. 8:1470-1479. 
22. Kim, T.H., Mars, W.M., Stolz, D.B., Petersen, B.E., and Michalopoulos, G.K. 1997. Extracellular matrix remodeling at the early stages of liver regeneration in the rat. Hepatology. 26:896-904.

23. Pikul, S., et al. 1998. Discovery of potent, achiral matrix metalloproteinase inhibitors. J. Med. Chem. 41:3568-3571.

24. Oda, T., et al. 2001. PAI-1 deficiency attenuates the fibrogenic response to ureteral obstruction. Kidney Int. 60:587-596.

25. Kivirikko, K.I., Laitinen, O., and Prockop, D.J. 1967. Modifications of a specific assay for hydroxyproline in urine. Anal. Biochem. 19:249-255.

26. Liu, Y., et al. 1999. Up-regulation of hepatocyte growth factor receptor: an amplification and targeting mechanism for hepatocyte growth factor action in acute renal failure. Kidney Int. 55:442-453.

27. Vukicevic, S., et al. 1992. Reconstituted basement membrane (Matrigel) promotes the survival and influences the growth of murine tumors. Int. J. Cancer. 50:791-795.

28. Tisher, C.C., and Madsen, K.M. 1996. Anatomy of the kidney. In The Kidney. B.M. Brenner, editor. 5th edition. W.B. Saunders Co. Philadelphia, Pennsylvania, USA. 3-71.

29. Douthwaite, J.A., Johnson, T.S., Haylor, J.L., Watson, P., and El Nahas, A.M. 1999. Effects of transforming growth factor-beta1 on renal extracellular matrix components and their regulating proteins. J. Am. Soc. Nephrol. 10:2109-2119.

30. Liu, Y. 1998. The human hepatocyte growth factor receptor gene: complete structural organization and promoter characterization. Gene. 215:159-169.

31. Bissell, D.M., Roulot, D., and George, J. 2001. Transforming growth factor beta and the liver. Hepatology. 34:859-867.

32. Steinmann-Niggli, K., Ziswiler, R., Kung, M., and Marti, H.P. 1998. Inhibition of matrix metalloproteinases attenuates anti-Thy1.1 nephritis. J. Am. Soc. Nephrol. 9:397-407.

33. Lelongt, B., Legallicier, B., Piedagnel, R., and Ronco, P.M. 2001. Do matrix metalloproteinases MMP-2 and MMP-9 (gelatinases) play a role in renal development, physiology and glomerular diseases? Curr. Opin. Nephrol. Hypertens. 10:7-12.

34. Zeisberg, M., et al. 2001. Renal fibrosis: collagen composition and assembly regulates epithelial-mesenchymal transdifferentiation. Am. J. Pathol. 159:1313-1321.

35. Zeisberg, M., Maeshima, Y., Mosterman, B., and Kalluri, R. 2002. Renal fibrosis. Extracellular matrix microenvironment regulates migratory behavior of activated tubular epithelial cells. Am. J. Pathol. 160:2001-2008.

36. Danen, E.H., and Yamada, K.M. 2001. Fibronectin, integrins, and growth control. J. Cell. Physiol. 189:1-13.

37. Yang, J., and Liu, Y. 2002. Blockage of tubular epithelial to myofibroblast transition by hepatocyte growth factor prevents renal interstitial fibrosis. J. Am. Soc. Nephrol. 13:96-107.

38. Okada, H., Inoue, T., Suzuki, H., Strutz, F., and Neilson, E.G. 2000. Epithelial-mesenchymal transformation of renal tubular epithelial cells in vitro and in vivo. Nephrol. Dial. Transplant. 15:44-46.

39. Strutz, F., and Muller, G.A. 2000. Transdifferentiation comes of age. Nephrol. Dial. Transplant. 15:1729-1731.

40. Li, J.H., et al. 2002. Smad7 inhibits fibrotic effect of TGF-beta on renal tubular epithelial cells by blocking smad 2 activation. J. Am. Soc. Nephrol. 13:1464-1472.

41. Mars, W.M., Kim, T.H., Stolz, D.B., Liu, M.L., and Michalopoulos, G.K. 1996. Presence of urokinase in serum-free primary rat hepatocyte cultures and its role in activating hepatocyte growth factor. Cancer Res. 56:2837-2843

42. Mizuno, K., Takehara, T., and Nakamura, T. 1992. Proteolytic activation of a single-chain precursor of hepatocyte growth factor by extracellular serine-protease. Biochem. Biophys. Res. Commun. 189:1631-1638.
43. Somerset, D.A., Strain, A.J., Afford, S., Whittle, M.J., and Kilby, M.D 2000. Hepatocyte growth factor activator (HGF-A) and its zymogen in human placenta. Placenta. 21:615-620.

44. Chevalier, R.L., Kim, A., Thornhill, B.A., and Wolstenholme, J.T. 1999. Recovery following relief of unilateral ureteral obstruction in the neonatal rat. Kidney Int. 55:793-807.

45. Chevalier, R.L., Thornhill, B.A., and Chang, A.Y. 2000. Unilateral ureteral obstruction in neonatal rats leads to renal insufficiency in adulthood. Kidney Int. 58:1987-1995.

46. Chevalier, R.L., Thornhill, B.A., Chang, A.Y., Cachat, F., and Lackey, A. 2002. Recovery from release of ureteral obstruction in the rat: relationship to nephrogenesis. Kidney Int. 61:2033-2043.

47. Andrews, K.L., et al. 2000. Gelatinase B (MMP-9) is not essential in the normal kidney and does not influence progression of renal disease in a mouse model of Alport syndrome. Am. J. Pathol. 157:303-311.

48. Keverne, E.B. 1997. An evaluation of what the mouse knockout experiments are telling us about mammalian behaviour. Bioessays. 19:1091-1098.

49. Eddy, A.A., Kim, H., Lopez-Guisa, J., Oda, T., and Soloway, P.D. 2000. Interstitial fibrosis in mice with overload proteinuria: deficiency of TIMP-1 is not protective. Kidney Int. 58:618-628.

50. Seeds, N.W., Basham, M.E., and Haffke, S.P. 1999. Neuronal migration is retarded in mice lacking the tissue plasminogen activator gene. Proc. Natl. Acad. Sci. USA. 96:14118-14123.

51. Siconolfi, L.B., and Seeds, N.W. 2001. Mice lacking tPA, uPA, or plasminogen genes showed delayed functional recovery after sciatic nerve crush. J. Neurosci. 21:4348-4355.

52. Brodsky, S., et al. 2001. Plasmin-dependent and -independent effects of plasminogen activators and inhibitor-1 on ex vivo angiogenesis. Am.J. Physiol. Heart Circ. Physiol. 281:H1784-H1792.

53. Mori, T., et al. 2001. Reduced cortical injury and edema in tissue plasminogen activator knockout mice after brain trauma. Neuroreport. 12:4117-4120

54. Ma, Z., Webb, D.J., Jo, M., and Gonias, S.L. 2001. Endogenously produced urokinase-type plasminogen activator is a major determinant of the basal level of activated ERK/MAP kinase and prevents apoptosis in MDA-MB-231 breast cancer cells. J. Cell Sci. 114:3387-3396.

55. Jo, M., Thomas, K.S., Somlyo, A.V., Somlyo, A.P., and Gonias, S.L. 2002. Cooperativity between the Ras-ERK and Rho-Rho kinase pathways in urokinase-type plasminogen activator-stimulated cell migration. J. Biol. Chem. 277:12479-12485.

56. Eddy, A.A. 2002. Plasminogen activator inhibitor-1 and the kidney. Am J. Physiol. Renal. Physiol. 283:F209-F220.

57. Reilly, T.M., Greenplate, G., and Timmermans, P.B. 1989. Tissue plasminogen activator-induced secretion of type-1 plasminogen activator inhibitor in cultured human fibroblasts. Thromb. Res. 55:619-625.

58. Lau, H.K., and Ho, J. 2002. Regulation of plasminogen activator inhibitor-1 secretion by urokinase and tissue plasminogen activator in rat epithelioid-type smooth muscle cells. Br. J. Haematol. 117:151-158.

59. Tsirka, S.E., Rogove, A.D., Bugge, T.H., Degen, J.L., and Strickland, S. 1997. An extracellular proteolytic cascade promotes neuronal degeneration in the mouse hippocampus. J. Neurosci. 17:543-552.

60. Rogove, A.D., Siao, C., Keyt, B., Strickland, S., and Tsirka, S.E. 1999. Activation of microglia reveals a non-proteolytic cytokine function for tissue plasminogen activator in the central nervous system. J. Cell Sci. 112:4007-4016.

61. Nakamura, T., et al. 1989. Molecular cloning and expression of human hepatocyte growth factor. Nature. 342:440-443.

62. Han, S., Stuart, L.A., and Degen, S.J. 1991. Characterization of the DNF15S2 locus on human chromosome 3: identification of a gene coding for four kringle domains with homology to hepatocyte growth factor. Biochemistry. 30:9768-9780. 